\title{
Unsteady High Velocity Flood Flows and the Development of Rating Curves in a Himalayan Basin under Climate Change Scenarios
}

\author{
Vishal Singh ${ }^{1}$ and Manish Kumar Goyal, Aff.M.ASCE ${ }^{2}$
}

\begin{abstract}
Hydrologic models are not able to compute unsteady flood flows, and the hydraulic models are sometimes found less effective in uncertainty estimation in the modeling outcomes. This study presents a coupled modeling framework to analyze the unsteady flows in the downstream of the Teesta and Lachung Rivers using hydrodynamic and hydrological models. The present approach leads to unsteady flow simulations along stream channel reach. Soil and Water Assessment Tool (SWAT) model is used for the projection of streamflow, water depth, and precipitation at various gauged and ungauged locations over the selected catchment using Coupled Model Intercomparison Phase 5 (CMIP5) CM3 model data sets with their representative concentration pathway (RCP) experiments and observed hydrometeorological data. SWAT-based projected scenarios are incorporated in the hydrodynamic model for the projection of water level, flood discharge, and flooded area at different sections in the downstream of the Teesta and Lachung Rivers. Using projected flood flows and water-level data, the rating curve equations have been developed at the outlets such as Chungthang and Lachung. The study outcomes resulting from both models show a very good agreement between the simulated streamflow and observed streamflow at the outlet locations. The uncertainties can also be associated in the modeling outcomes. Thus, a statistical-cum-stochastic downscaling method has been applied to downscale the CMIP5 CM3 model-based meteorological variables (e.g., temperature and precipitation). The modeling errors prior to project streamflow have been adjusted using a sequential parameter fitting approach (SUFI2). The hydrodynamic model-based projected unsteady flood flows are found highly uncertain in the downstream portion of both rivers, and thus several extreme flood peaks have been observed in the final outcomes. The observations show that the water velocities have increased in the projected scenarios (recorded as $8.5 \mathrm{~m} / \mathrm{s}$ ), as compared to historical scenarios $(6.5 \mathrm{~m} / \mathrm{s})$. Using projected time series discharge and water level (stage), the rating curve equations, which have been developed as per the low to extreme emission scenarios, can be used in the future planning and management of the water resources systems. DOI: 10.1061/ (ASCE)HE.1943-5584.0001530. (C) 2017 American Society of Civil Engineers.
\end{abstract}

Author keywords: Hydrodynamic model; Soil and Water Assessment Tool (SWAT); Coupled Model Intercomparison Phase 5 (CMIP5) CM3 GCM; Rating curves; Design flow; Teesta River.

\section{Introduction}

The Himalayan rivers such as the Lachung and Teesta Rivers contribute their flow from snow-glacier melting throughout the year. Therefore, current climatic uncertainties can significantly affect the downstream flow of these two rivers (Singh and Goyal 2016b). The hydroclimatology of the Teesta River catchment is very dynamic because the upstream portion belongs to moderate to extreme highelevation zones (from 1,400 to 7,400 m) (Krishna 2005), thus in extreme flood discharge conditions, the water velocity can be disastrous. Therefore, an accurate estimation of river flow is necessary in the downstream portion for flood management. A few studies revealed that due to climate change, the precipitation and discharge amount will be enhanced in the streams in future (Singh et al. 2015; Karahan et al. 2013). The relationship between the river discharge and water level (stage) or rating curves are thus important to design

${ }^{1}$ Ph.D. Research Scholar, Dept. of Civil Engineering, Indian Institute of Technology, Guwahati, Assam 781039, India.

${ }^{2}$ Assistant Professor, Dept. of Civil Engineering, Indian Institute of Technology, Guwahati, Assam 781039, India (corresponding author). E-mail: mkgoyal@iitg.ernet.in

Note. This manuscript was submitted on February 23, 2016; approved on January 26, 2017; published online on June 1, 2017. Discussion period open until November 1, 2017; separate discussions must be submitted for individual papers. This paper is part of the Journal of Hydrologic Engineering, (C) ASCE, ISSN 1084-0699. hydraulic structures of a flood management project and in the making of reservoir releasing policy (Rahman et al. 2011).

An analysis of river water level at various cross sections using a physically based flood routing hydrodynamic model is quite weighty because it requires large numbers of data sets such as time series discharge, river morphometric parameters, river hydraulics variables, bed resistance, and roughness coefficients (Vansteenkiste et al. 2013; Doulgeris et al. 2012). Several research studies demonstrated a successful utilization of hydrodynamic models in flood routing and stage-discharge computations using measured cross sections and time series data sets (Doulgeris et al. 2012; Rahman et al. 2011; Thompson et al. 2009; Patro et al. 2009). These models require precise river geometric data, which is difficult to measure at the desired study area locations because a few studies also reported several instability issues in the river flow hydrodynamic models (Rahman et al. 2011; Thomson et al. 2004). The one dimensional (1D) hydrodynamic model MIKE 11 has already proved its capabilities in the hydrodynamic computation of design flow, water levels, and water velocity around the world (DHI 2004; Doulgeris et al. 2012; Rahman et al. 2011; Thomson et al. 2004).

Several studies found that the occurrences of extreme precipitation events and flood discharges are increased and will be frequent in the 21st century because of climate change (Singh et al. 2015; Karahan et al. 2013). Floods are one of the main causes of the destruction of physical property and life (Karahan et al. 2013). Many studies used the latest Coupled Model Intercomparison 
Phase 5 (CMIP5) climate model data sets in the forecasting of precipitation extreme events and flood discharge through hydrologic models such as the Soil and Water Assessment Tool (SWAT) (Singh et al. 2015, 2013; Zucco et al. 2015; Taylor et al. 2012; Abbaspour 2011). A few studies significantly highlighted the severity of extreme events and high volume discharge over Himalayan catchments (Singh and Goyal 2016a; Singh et al. 2015; Goyal 2014; Goyal and Ojha 2010). The CMIP5 model ensembles are determined by the emission scenarios reliable with the representative concentration pathway (RCP) experiments (RCP2.6, RCP4.5, and RCP8.5), which explores an estimate of the radiative forcing (RF) in the 21 st century (Change 2013; Taylor et al. 2012). The RCP8.5 is categorized as the high emission scenarios experiment, and as per RCP8.5, $\mathrm{RF}$ will be increased in the 21st century. Likewise, the RCP2.6 and RCP4.5 are the intermediate scenarios (Taylor et al. 2012).

This study aimed to compute (1991-2005) and project (20082100) the flood discharge, water level, and water velocity by coupling the hydrological model SWAT and hydrodynamic model MIKE 11. A Sequential Uncertainty Parameter Fitting version 2 (SUFI2) method has been performed to reduce the model uncertainties and the modeling outcomes (Singh et al. 2013; Abbaspour 2011). To compute and project the flood discharge, water level, and water velocity in MIKE 11, initially, the streamflow discharge scenarios at different catchment outlets were generated in SWAT model using CMIP5 CM3 based on the RCP experiments. SWAT is fully capable of simulating and projecting the streamflow scenarios using climate model data, while MIKE 11 is fully able to compute the design flow, water level, and water velocity. Another prime objective of this study was to develop the rating curve equations at various cross sections/chainages (Ch) of the Teesta and Lachung Rivers using RCP experiments based on projected water level and discharge data. To maintain the accuracy level in modeling outcomes, several field surveys were carried out to measure the cross sections along the Teesta and Lachung Rivers. However, due to the remote locations and very high elevated topography of the Teesta and Lachung Rivers, the majority of cross sections using a very high spatial resolution cartographic satellite (CARTOSAT) digital elevation model (DEM) $(10 \mathrm{~m})$.

\section{Physical Geography and Hydroclimatology of the Study Area}

A Teesta River catchment (up to Chungthang gauge station) that is also a part of north Sikkim Himalaya Sikkim state of India has been selected for the study. Lachung is one of the major tributaries of the Teesta River and also a part of the Teesta River catchment included in the study work. In this study, the Chungthang and Lachung gauge stations as outlets of the Teesta and Lachung Rivers, respectively (Fig. 1). The origin point of the Teesta River is Chhombo Chhu from a glacial lake named Khangchun Chho at an elevation of 5,280 $\mathrm{m}$ in the north Sikkim eastern Himalayas (Krishna 2005). Teesta River has many small and big tributaries. Many shorter course streams meet the Teesta River on the eastern flank, while the larger tributaries meet on the western flank. These tributaries contribute a large amount of drainage to the main Teesta River.

The Teesta River catchment is influenced mainly by the southwest monsoon, which normally sets in around mid-June and withdraws by the end of September. The average normal precipitation in Sikkim is about $2,534 \mathrm{~mm}$. The Teesta basin upstream portion is mainly fed by snowfall during winters, and the downstream portion is fed by rainfall in summer. Due to the high altitudinal variations over the upstream catchment parts of Teesta River, the meteorological factors (e.g., temperature and precipitation) show high variability across their subcatchments. The upstream portion of the catchment corresponded to very high elevations $(7,000 \mathrm{~m})$, and the downstream portion of the catchment corresponded to moderate elevations $(1,400 \mathrm{~m})$. Thus, temperature lapse rate (TLR) also varies from downstream to upstream parts of the catchment (Singh and Goyal 2016a; Gardner et al. 2009). The Teesta River catchment receives around $75 \%$ of the rainfall during monsoon season (June-September). The Teesta River catchment receives the maximum amount of precipitation from June to August, while maximum snowfall is received during February and March (Krishna 2005).

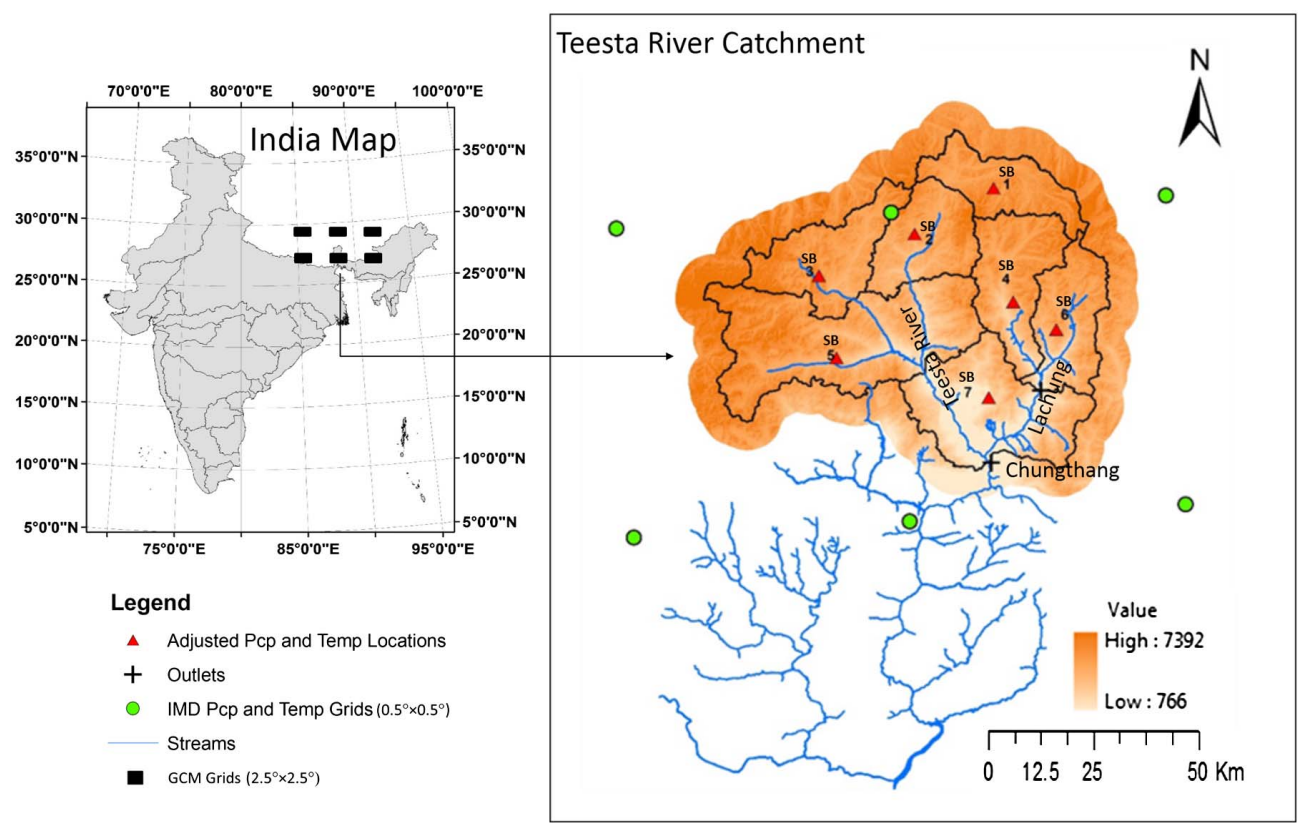

Fig. 1. Map of the study area 


\section{Methodology and Data Sets}

\section{Description of SWAT Model}

SWAT is deterministic, semidistributed, and continuous time hydrological model, which is capable of simulating and forecasting various water balance components on a daily, monthly, and annual basis. SWAT is fully capable of simulating and forecasting surface water parameters and snow melt hydrology parameters on the subcatchment and point scales (Ficklin and Barnhart 2014; Neitsch et al. 2011; Arnold et al. 2012). Each subcatchment contains the main channel and many hydrologic response units (HRUs), which consist of homogeneous land use/land cover (LULC), soil types and slope. Around 2,400 peer-reviewed publications are available related to SWAT model applications, thus the model equations and their theoretical description have been avoided in this research article (Singh et al. 2015, 2013; Ficklin and Barnhart 2014; Arnold et al. 2012; Neitsch et al. 2011; Jain et al. 2010; Abbaspour et al. 2007). The weather generator parameters, such as daily precipitation, daily minimum and maximum temperature, daily humidity, daily wind speed, and daily net solar radiation are necessarily required to set up the SWAT model. The physical and topographical parameters, such as LULC, soil, and DEM, are required to generate the drainage and physiographical characteristics of the selected study region.

In SWAT, streamflow is computed at each HRU and subcatchment scale using soil conservation services (SCS) curve number (CN) method (Arnold et al. 2012). Several authors reported that are necessary to be modified as per the HRU slopes because several time extreme peaks are observed in simulated discharge (Singh et al. 2015). Thus for the current study area, CNs are modified according to HRU slopes by the equation given by Mishra et al. (2014). In SWAT, there is a limited scope for CN modifications (Neitsch et al. 2011). Therefore, SWAT-based generated CNs are exported from the SWAT management database then CNs are modified as per the HRU slopes. For $\mathrm{CN}$ modification, a modified CN equation was used (Huang et al. 2006; Mishra et al. 2014) then SWAT-derived CNs are adjusted as per the respective classes (Mishra et al. 2014). The modified $\mathrm{CN}$ table is given as supplemental data. In SWAT, the main hydrological component, such as runoff, is simulated for each HRU, and the contributions of each HRU are then aggregated for the subcatchment by a weighted average. Water is then routed to the main outlet of the catchment (Neitsch et al. 2011).

\section{SWAT-Based Calibration and Uncertainty Analysis}

Streamflow simulation and validation were done using SWAT-CUP (Abbaspour et al. 2007), which takes SWAT-simulated outcomes. For the model calibration and validation, the daily discharge time series data sets were used at the two outlet locations (such as Lachung and Chungthang) for the years 1989-2005. The measured streamflow data sets were collected from the Central Water Commission (CWC), India. The model calibration has been performed using the concept of aggregate parameter selection method (Abbaspour 2011). An aggregate parameter is defined by adding a term such as $v_{-}, a_{-}$, and $r_{-}$to the front of the original parameter to mean a replacement, an absolute increase, and a relative change to the initial parameter value, respectively (Zhang et al. 2014). The goodness-of-fit criteria using coefficient of determination $\left(R^{2}\right)$ and Nash-Sutcliffe Equation (NSE) (Nash and Sutcliffe 1970) were used for the evaluation of streamflow at all the gauging outlets (Zhang et al. 2014; Abbaspour et al. 2007).

\section{Parametric Uncertainty and Sensitivity Analysis Approach}

The hydrological model consists of deterministic description of precipitation, discharge, evapotranspiration (ET), storage, and transport processes. A deterministic hydrological model such as SWAT is not fully able to explore the stochastic behavior of the random variables, such as precipitation and resultant discharge (Zhang et al. 2014; Singh et al. 2013; Abbaspour et al. 2007). Calibration of any distributed hydrological model using observed hydro-observation data sets always leads to the nonidentifiable parametric uncertainties due to an involvement of the complex hydrological processes and relevant data sets (Zhang et al. 2014). Many authors found that model parameterization and uncertainty analysis can reduce the various input data uncertainties and parameter-related uncertainties in the simulated and projected modeling outcomes (Singh et al. 2013; Abbaspour et al. 2007).

As per the above considerations, the SUFI2, a stochastic optimization method, has been selected to overcome the model uncertainty issues in streamflow computation (Zhang et al. 2014; Abbaspour et al. 2007). SUFI2 is a Bayesian inference system, which operates parametric uncertainty within the uncertainty domains (prior and posterior) associated with each parameter using stratified Latin hypercube sampling (Singh et al. 2015; Abbaspour 2011; Abbaspour et al. 2007).

Parameter uncertainty is usually caused as a result of inherent nonuniqueness of parameters (involved model calibration parameters) in inverse modeling due to wrong data inputs and parameterization. The adaptation of inverse modeling approach is a very popular method for the model calibration (Abbaspour et al. 2007). In SUFI 2, an iterative process run for the model calibration and it tries to maximize the given objective function, such as $R^{2}$ and NSE. Each iteration comprises a number of simulation steps and finds the optimal solution in each stratified random sample interval. In each simulation, it modifies the parameter ranges, and once the function is maximized, the fitted parameter coefficient values corresponding to the given objective function values are given (Singh et al. 2013; Abbaspour et al. 2007).

The SUFI2 algorithm basically assumes a large parameter uncertainty to ensure the observed data fall into the 95 percent prediction uncertainty (95PPU) band for the first iteration and decrease the uncertainty in steps while monitoring the $\mathrm{p}$-factor and $\mathrm{r}$-factor for the next several iterations (Abbaspour et al. 2007). The p-factor determines the percentage of simulated data falls into the observed data set, and the r-factor determines the uncertainty thickness in the simulated data sets when compared to observed data sets. The 95PPU can be calculated between the 2.5 and $97.5 \%$ levels of the cumulative distribution of an output variable obtained through Latin hypercube sampling, disallowing $5 \%$ of the very bad simulations (Abbaspour 2011). The value of p-factor ranges between $0 \%$ and $100 \%$ and $r$-factor ranges between zero to infinity. It means that the value of $\mathrm{p}$-factor $=1$ and $\mathrm{r}$-factor $=0$ corresponds to measured data equivalent to observed data. The values are computed far from these values and can be utilized to judge the strength of the calibration. A larger p-factor can be achieved at the expense of a larger r-factor (Abbaspour 2011). The mathematical expressions of the SUFI2 algorithm are defined in the SWAT-CUP user manual (Abbaspour 2011).

In this study, a total of five calibration parameters were taken for the calibration and validation. The sensitivity of model calibration parameters has been ranked using p-value and t-stat using the global sensitivity analysis (GSA) method (Zhang et al. 2014; Singh et al. 2013; Abbaspour 2011). In GSA outcomes, a significance test (t-stat) is evaluated based on the significance level alpha $(\alpha=0.05)$ 
and $p$-values. The alpha value of 0.05 was chosen as the local significance level. Based on this significance level, values larger than 1.96 or lower than -1.96 , respectively, indicate a significant $(p<0.05)$ positive or negative trend. If the $p$-value will be closer to zero, the corresponding values will be more significant for the trend (Singh et al. 2013; Abbaspour 2011).

\section{Coupling of SWAT-MIKE 11 and Their Boundary Conditions}

MIKE 11 has many modules such as rainfall-runoff (RR), hydrodynamic (HD), advection-dispersion (AD), water quality, and DAM break analysis (Patro et al. 2009; DHI 2004). In this study, the MIKE 11 HD module has been used for the Teesta and Lachung Rivers and thus coupled with SWAT to analyze flood discharge and rating curves in historical (1991-2005) and future time series domains (2008-2100). The fully hydrodynamic approach in MIKE 11 was performed to compute various HD variables, such as discharge and water level. The HD model setup is grouped into various sections, such as river network linking, river cross section and conveyance definition, boundary condition, HD parameter setup, and simulation time step. Stage in the Teesta River is also influenced during the flood period by other rivers that have also been considered in the river network and calculated from the cross sections. The HD parameter details are given in Table 1 . MIKE 11 results from high order fully hydrodynamic wave formulation are the derivations of the Saint Venant equations (Soleymani and Delphi 2012; Rahman et al. 2011; Thompson et al. 2004).

Boundary conditions in MIKE 11 are defined by combined use of time series data prepared in the time series editor and specifications made on locations of boundary points and boundary types in the boundary editor. Initially, the location of the boundary point and the boundary description and type are specified. Location name is defined based on the river name and chainages. Initially at the inlet source, initial water depth and discharge were defined as per the information given by the SWAT model. During historical time computation, measured discharge data sets are used at the defined outlet locations, such as Lachung and Chungthang. The inlet source data sets were taken from the SWAT model. During projected time series, the inlet and outlet point data sets were taken from the SWAT model. The discharge taken as variable time series and water level is defined as constant variable in boundary condition. Wind shear stress is required for time variable boundary condition to evaluate the effect of wind on turbulence flow and thus it is included in the simulation (DHI 2004). Several cross sections (X-sections) were measured in the field and several computed from DEM input to define the rating curve equation. The cross-section data sets and conveyance factor are necessary parameters in hydrodynamic river flow modeling.

Accurate bathymetric data (or river depth information) are needed to compute accurate discharge and time-of-travel predictions. Full cross-sectional and longitudinal depth-profile data (10 cross sections) were collected, referenced to an elevation datum, in the main stem using Total Station Instrument. The longitudinal depth-profile data are useful in identifying all of the shallow and deep areas of the river channel, allowing interpolated cross sections to be created for a model grid that captures these characteristics of the channel. Additionally, around 25 cross sections were computed using CARTOSAT DEM at different locations in the Teesta and Lachung Rivers. In an ungauged catchment, the availability of hydrological and hydrodynamic parameters, which are required for modeling, are sometimes limited. Because of these above considerations, MIKE 11 has coupled with SWAT to fulfill all the objectives taken in this study. The coupled diagram of MIKE 11 and SWAT are shown in Fig. 2.

The stream channel network and catchment area initially delineated in the SWAT model is used in MIKE 11. For the stream network extraction, multispectral high-resolution Indian Remote Sensing Satellite (IRS) Linear Imaging Spectral Scanner (LISS) 3 (2009) imagery, downloaded from the BHUWAN (www.bhuwan .nrsc.gov.in) portal, is used in this study. For the catchment and subcatchment boundary delineations, a high resolution CARTOSAT DEM was used. SWAT classifies the LULC and river geometry at hydrological response unit spatial scale (Abbaspour et al. 2007;

Table 1. MIKE 11 HD Model Parameters and Their Descriptions

\begin{tabular}{|c|c|c|c|}
\hline Parameter & Factor & Method/values & Description \\
\hline Initial parameters & $\begin{array}{l}\text { Initial discharge } \\
\text { Initial depth }\end{array}$ & $\begin{array}{c}10 \mathrm{~m}^{3} / \mathrm{s} \\
0.5 \mathrm{~cm}\end{array}$ & $\begin{array}{l}\text { Discharge } \\
\text { Water-level depth }\end{array}$ \\
\hline Wind factor & $\begin{array}{l}\text { Friction factor } \\
\text { Topographical factor }\end{array}$ & $\begin{array}{c}0.0024 \\
1\end{array}$ & $\begin{array}{l}\text { Friction parameter value } \\
\text { Slopes }\end{array}$ \\
\hline Bed resistant & $\begin{array}{l}\text { Resistance number } \\
\text { Approach } \\
\text { Resistance formula }\end{array}$ & $\begin{array}{c}10-15(10-100) \\
\text { Uniform section } \\
\text { Manning's/Chezy's } \\
\text { Number/0.010-0.015 s m }{ }^{-1 / 3}\end{array}$ & Manning parameter \\
\hline $\begin{array}{l}\text { Wave approximation } \\
\text { Coefficient values }\end{array}$ & $\begin{array}{l}\text { Method } \\
\text { Delta } \\
\text { Delhs } \\
\text { Delh } \\
\text { Alpha } \\
\text { Theta } \\
\text { Eps } \\
\text { Dh node } \\
\text { Zeta minimum } \\
\text { Inter } 1 \text { maximum } \\
\text { Nolter } \\
\text { Maxlter steady } \\
\text { Froude maximum } \\
\text { Froude exp. }\end{array}$ & $\begin{array}{l}\text { High order fully dynamic } \\
0.6(0.5-1.0) \\
0.01 \\
0.1 \\
1 \\
1 \\
0.0001 \\
0.01 \\
0.1 \\
20 \\
1 \\
100 \\
-1 \\
-1\end{array}$ & $\begin{array}{l}\text { Routing method } \\
\text { For model stabilities } \\
\text { The minimum allowable water-level differences across a weir } \\
\text { Controls the dimensions } \\
\text { Velocity distribution coefficient } \\
\text { A weighting factor for momentum equation } \\
\text { Water surface slope uses in diffusive wave equation } \\
\text { Computational coefficient } \\
\text { Minimum head loss coefficient } \\
\text { Maximum number of iterations } \\
\text { No iterations } \\
\text { Maximum number of iterations for steady condition } \\
\text { Suppression term for convective acceleration } \\
\text { Suppression term for convective acceleration }\end{array}$ \\
\hline
\end{tabular}




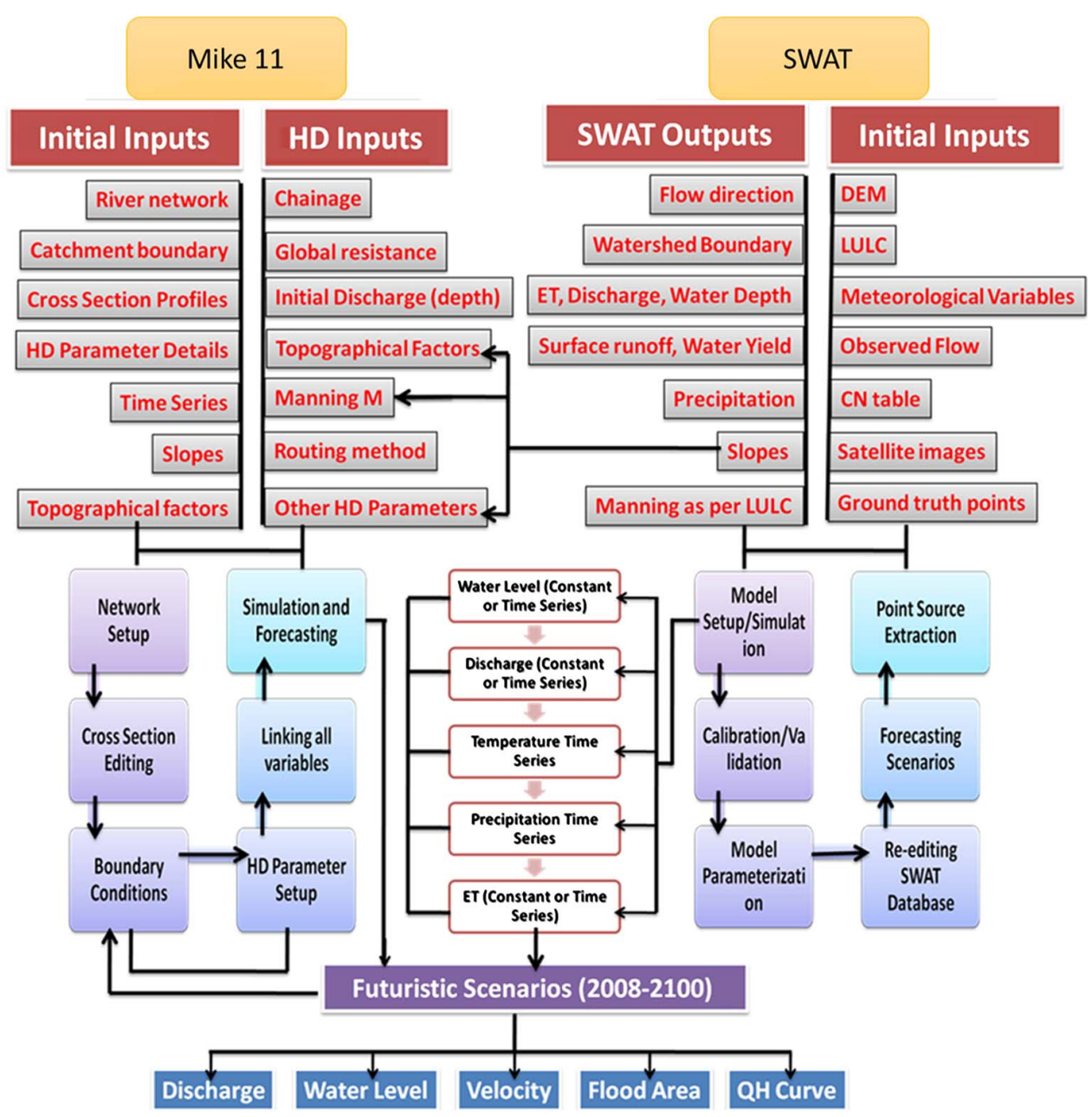

Fig. 2. Methodology chart of coupled framework using MIKE 11 and SWAT

Arnold et al. 2012); thus Manning's roughness coefficient generated at each HRU level near to stream in SWAT was used in MIKE 11 because SWAT calculates the accurate Manning's roughness coefficient $n$ value at each HRU using LULC and slopes (Neitsch et al. 2011). Channel and floodplain resistance factors for the given cross sections are calculated in the cross section editor file in MIKE 11 (DHI 2004).

The boundary conditions (upstream and downstream), initial condition (time $t=0$ ) and stability parameters such as courant condition $(C r<1)$ to determine time step are necessary for the model simulation (Soleymani and Delphi 2012; Rahman et al. 2011). The stability and other hydrodynamic parameter details are given in Table 1. However, several assumptions relevant to design flow, water velocity, and cross sections associated with the governing equations are considered (DHI 2004).

\section{Spatial Interpolation and Climate Downscaling of Hydrometeorological Variables}

High-resolution daily gridded $\left(0.5^{\circ} \times 0.5^{\circ}\right)$ precipitation and temperature data sets for the period of 1980-2005 are available at the Indian Meteorological Department (IMD) and the Indian Institute of Tropical Meteorology (IITM) India and are used for the study. This data set is prepared from quality-controlled observed precipitation/rainfall data from more than 1,800 gauges and is increasingly being used in studies on the Indian and Himalayan continents (Subash and Sikka 2014). The two gauge stations, such as Lachung and Chungthang, point source measured daily precipitation data sets (1980-2005) were also available andused for study.

The whole catchment of the selected study area is divided into seven subcatchments (SB) to highlight the spatial variations in the climatological factors, such as temperature and precipitation. There are seven climate stations, such as Chopta Valley (at SB1), Thangu (at SB2), Muguthang (at SB3), Lachen (at SB4), Yumthang (at SB5), Lachung (at SB6), and Chungthang (at SB7), that were defined to project the local-scale changes associated with temperature and precipitation. Then, the gridded and measured precipitation and temperature data sets were adjusted at each SB (at different point locations) by calculating the TLR and precipitation lapse rate (PLR) (Singh and Goyal 2016a; Escurrat et al. 2014; Gardner et al. 2009). The TLR and PLR are calculated from CARTOSAT DEM, which was downloaded from BHUWAN portal. The detailed methodology of the TLR and PLR is earlier discussed by Singh and Goyal (2016a) and Neitsch et al. (2011).

After the spatial adjustment of observed hydrometeorological variables, the downscaling of daily temperature and precipitation data sets were performed at each climate station using climate model 3 (CM3) climate model with their RCP experiments (RCP2.6, RCP4.5, and RCP8.5). The six global circulation model $(\mathrm{GCM})$ grids (at $2.5^{\circ} \times 2.5^{\circ}$ scale) surrounding the study region were selected as the spatial domain of the 16 most relevant GCM 
predictors (Zhang et al. 2014; Taylor et al. 2012) to adequately cover the various circulation domains of the predictors considered in this study. These six GCM grid points are spatially interpolated at each climate station using an inverse distance weightage approach (IDWA) (Kharin et al. 2013; Goyal and Ojha 2010; Snell et al. 2000). The IDWA method interpolates the GCM grid points (for each predictor) at the known observed grid point (predictand, such as temperature and precipitation) as per the weighted average of each grid point.

The statistical downscaling model (SDSM) implies empirical relationships between the local-scale predictands and large-scale predictor(s) (Wilby et al. 2014; Mahmood and Babel 2013) and can be classified as a conditional and stochastic weather generator in which regression equations are used to estimate the parameters of daily minimum-maximum temperature and precipitation rate and amount, separately, so it is slightly more sophisticated than a straightforward regression model. The large-scale variable fields from GCMs or reanalysis data (NCEP predictors) are chosen such that they are strongly related to the local-scale conditions of interest (the predictands or response variable) (Singh and Goyal 2016b; Mahmood and Babel 2013).

Because of the linear concepts of SDSM, the selection of predictors was performed based on the correlation and partial correlation analysis between the interested predict and the predictors, and weights of the predictors which are estimated via ordinary least-square method (Mahmood and Babel 2013). Among the 16 predictors for GCMs, the negatively correlated predictors were dropped. Hence, out of 16 GCM predictors, finally 12 positive correlated predictors were selected for the Singh and Goyal (2016b). To select the first and most suitable large-scale variable, a more quantitative method has been adopted for screening large-scale variables for each local-scale variable at each of the climate stations (Singh and Goyal 2016b; Mahmood and Babel 2013).

In this method, first a correlation matrix between 12 reanalysis predictors for GCMs and the predictand (observed data) is prepared. Then, the predictors of a high-correlation coefficient were taken and arranged in descending order. The first-ranked predictor, having the highest correlation coefficient among the others, is selected and defined as the first suitable super predictor (FSSP) (Mahmood and Babel 2013). After this, the absolute correlation $(R)$ between predictor and predictand, and the correlation coefficient between individual predictors are also calculated. Then the other highly correlated predictors (for precipitation it is 0.5 and above, and for temperature it is 0.7 and above in this case) are taken out in order to remove any multi-colinearity. The correlation coefficient up to 0.7 between two predictors is acceptable (Singh and Goyal 2016b; Mahmood and Babel 2013).

The selection of the second, third, and so on reanalysis predictors was performed using percentage reduction in an absolute partial correlation (PRP) with respect to absolute correlation is calculated for each predictor (Singh and Goyal 2016b; Mahmood and Babel 2013). The PRP is the percentage reduction in partial correlation with respect to correlation coefficient. The predictor, which has a minimum PRP in partial correlation, is selected as the second most suitable predictor. As a result, this predictor has almost no or a very insignificant multicolinearity with the FSSP. The third, fourth, and following predictors could be obtained by repeating the same procedure. For the 21st century (2006-2060) scenario generation, the combined calibration/validation of the SDSM model is performed using daily observed minimum and maximum temperature, and precipitation data sets (predictands) with reanalysis NCEP predictors. For the model calibration and parameterization, SDSM is developed on monthly submodels. The model performance is evaluated using multiple evaluation methods such as $R^{2}, R M S E$, mean bias, and standard deviation (Singh and Goyal 2016b).

\section{Results and Discussions}

In this study, an unsteady flow routing model has been developed at different cross sections or chainage $(\mathrm{Ch})$ locations on the mainstream network of the Teesta and Lachung Rivers [Figs. 3(a and b)]. For the cross section definition, the mainstream network has been created in the model. If there is no difference in the stream channel length and floodplain flow paths from cross section to cross section, which have been given as input to the model, then model-computed output will be the same as compared to the observed data sets. The bathymetric survey data for several cross sections on the Lachung and Teesta Rivers has been shown in the Figs. 3(a and b). The water-level flow area and water-level conveyance relationships using observed discharge and water-level data sets at the main catchment outlets, such as Chungthang and Lachung have been shown in Fig. 3(c). The conveyance (K) has been calculated based on the roughness coefficient $n$ by calculating hydraulic radius (DHI 2004).

Channel and floodplain resistance factors for the given cross sections are calculated in the cross section editor file in MIKE 11. Initially, the MIKE 11 unsteady flow model was set up by applying the default constant value of roughness coefficients. The default value of $n$ is taken as $0.045 \mathrm{~s} / \mathrm{m}^{1 / 3}$ (DHI 2004). As per the initial runs and computed outcomes, the model overpredicted the water level and discharge. Therefore, for the implementation of local roughness coefficient as per the existing slope and LULC conditions, the Manning's roughness coefficient $n$ value for each cross section is adopted from the SWAT model. SWAT calculates the accurate Manning's roughness coefficient $n$ value at each HRU using LULC and slopes as defined in Table 1. The constant roughness coefficient as suggested by the Danish Hydraulic Institute (DHI) (2004) is insignificant for this study due to the slope variations and LULC variations. For this study area, the Manning's roughness coefficient $n$ that ranges from 0.010 to $0.015 \mathrm{~s} / \mathrm{m}^{1 / 3}$ (Table 1 ) is adopted, which is almost same value revealed by other researchers (Neitsch et al. 2011).

To define the boundary conditions, SWAT-based generated discharge data sets at several point locations over the selected study area were used. For the outlet locations, observed discharge data sets were input in model. To make the data readable in MIKE 11, the discharge data sets from SWAT and observed gauges are converted according to MIKE 11 specified format. To fulfil the boundary conditions and for the model stability conditions, several hydrodynamic parameters are adopted as per literature survey and measurements. The HD parameters, given in Table 1, are calculated from SWAT, and some of them are taken as the global values (DHI 2004). The hydrodynamic parameter file requires bed and floodplain resistance data sets for the river network. Bed and floodplain are input as Manning's roughness coefficient $n$ values. The resistance factor is input from one point to another point along the river flow path. Any local differences in resistance can be given to the cross section file at a specific cross section. The Delta and Delhs coefficients were found very sensitive parameters for the stability conditions. The best Delta value was 0.6 after doing several trial and error computations. All the input data sets and boundary layers were set up into the SWAT simulation file. The Teesta slopes correspond with very steep slopes thus the model run time is taken as $1 \mathrm{~min}$ to find the stability conditions. The initial water-level depth and streamflow information computed from measured streamflow and field survey measurement were provided to avoid a dry bed situation in the simulation. 


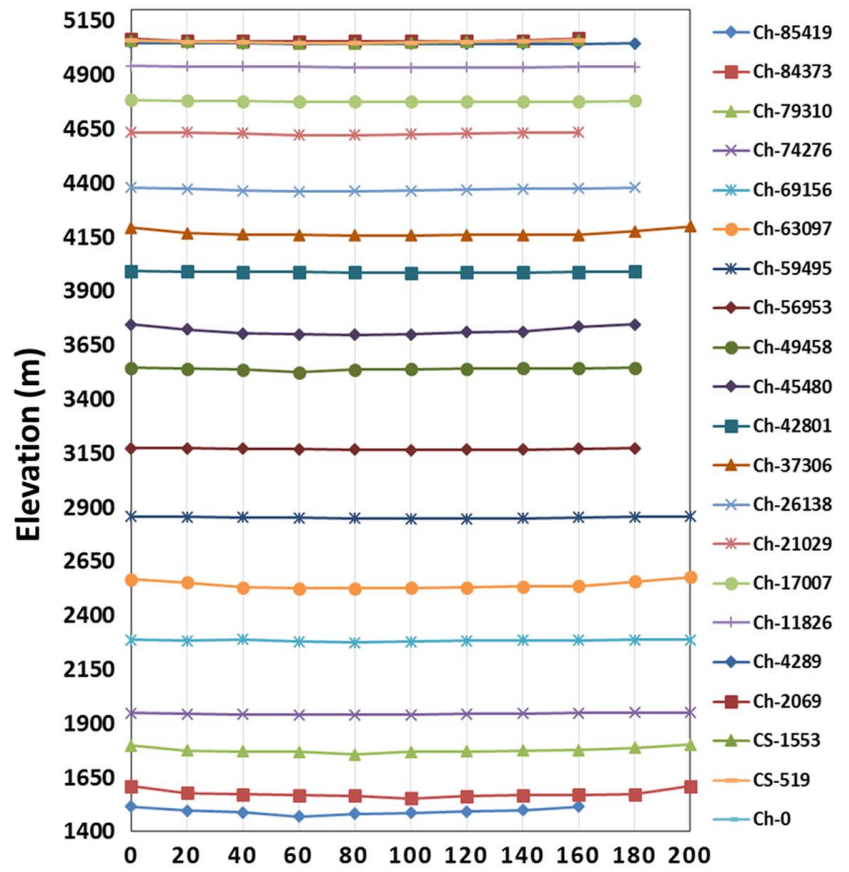

(a)

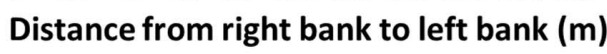

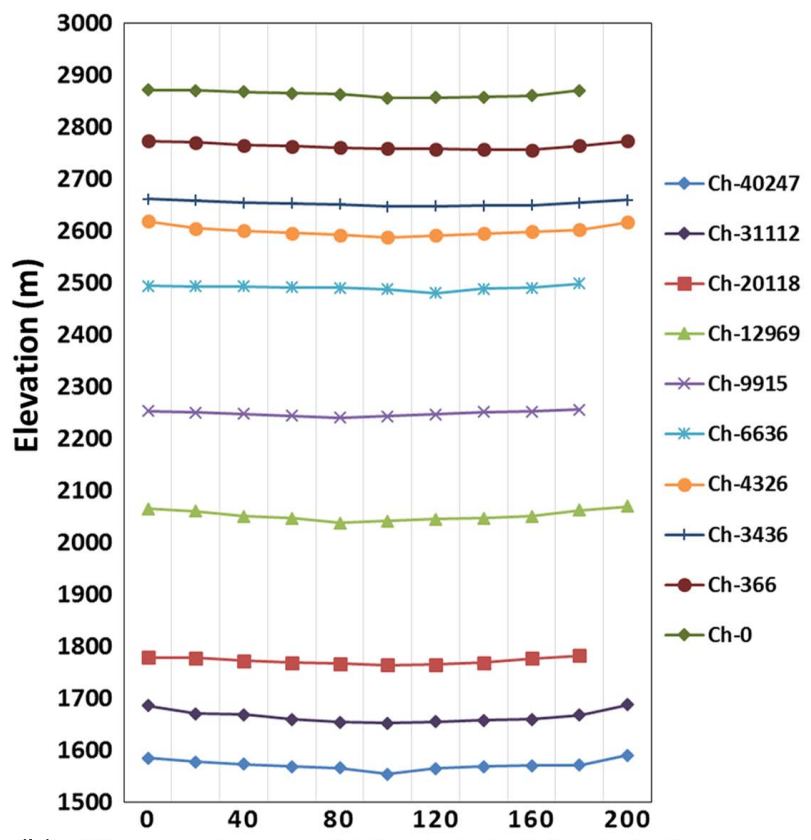

(b) Distance from right bank to left bank (m)
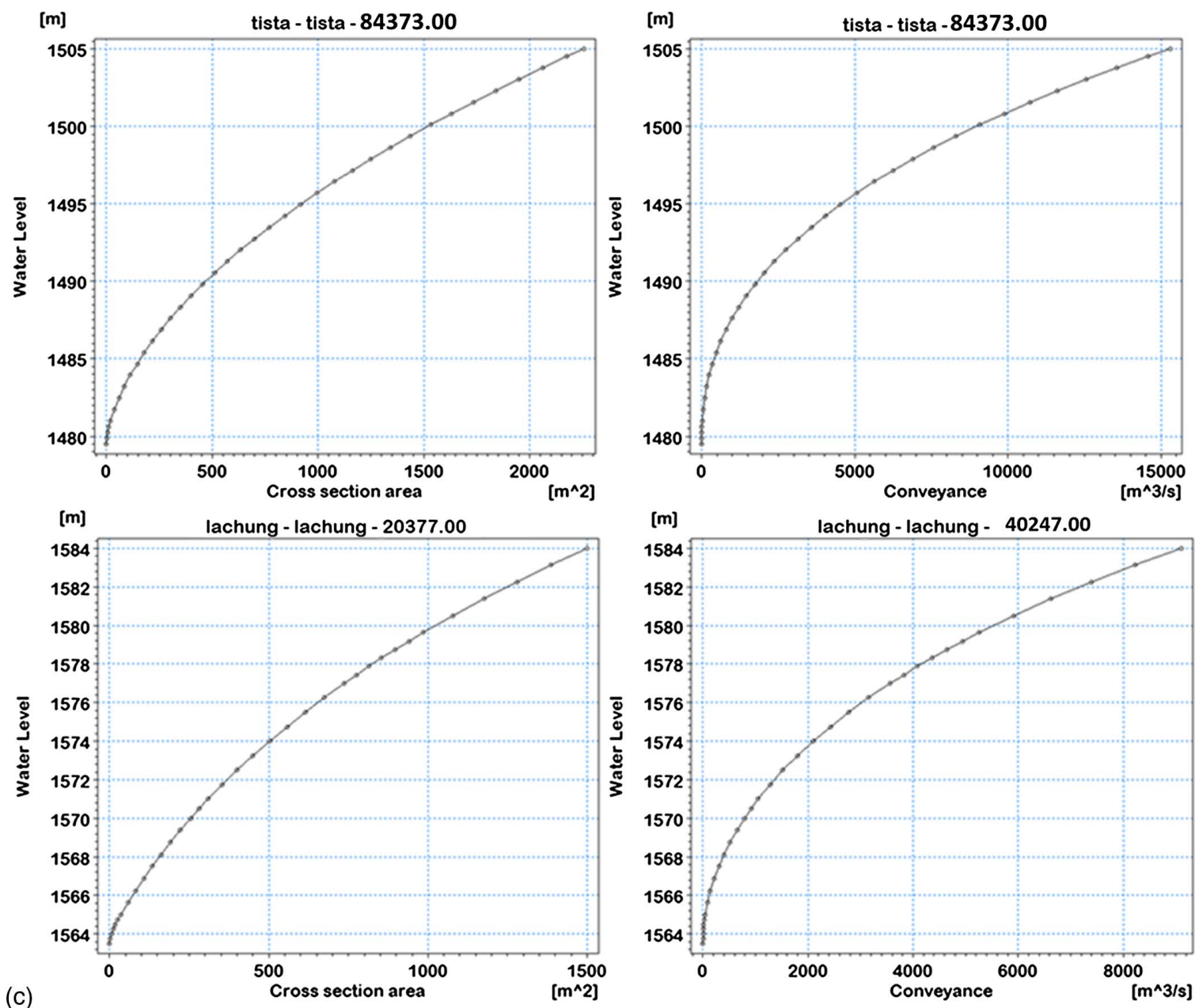

Fig. 3. (a) Cross section detail for Teesta River; (b) cross section details for Lachung River; (c) cross section area versus water level at both the outlet locations, such as Chungthang and Lachung 
Table 2. SUFI2-Based Model Calibration and Validation Results on a Daily Basis

\begin{tabular}{lclcccc}
\hline $\begin{array}{l}\text { Time } \\
\text { step }\end{array}$ & $\begin{array}{c}\text { Calibration/ } \\
\text { validation }\end{array}$ & \multicolumn{1}{c}{ Outlet } & p-factor & r-factor & $R^{2}$ & NS \\
\hline Daily & \multirow{2}{*}{ Calibration } & Lachung & 0.48 & 0.32 & 0.52 & 0.38 \\
& & Chungthang & 0.58 & 0.14 & 0.62 & 0.46 \\
& \multirow{2}{*}{ Validation } & Lachung & 0.54 & 0.45 & 0.60 & 0.53 \\
& & Chungthang & 0.55 & 0.45 & 0.61 & 0.77 \\
\hline
\end{tabular}

MIKE 11 has been calibrated for the historical period from 1989 to 2005. The initial two years (1989-1990) are taken as a warmup period, hence the results are shown from 1991 to 2005. The observed discharge data sets are available at Teesta and Lachung gauges, hence MIKE 11-generated discharge data sets were compared at both the outlet gauge locations' gauges. Based on the observed data inputs, water level, water velocities, flooded area, and discharge have been computed at different downstream chainages. Based on the computed discharge and water level, stage-discharge (Q-h) rating curves at different changes of the Teesta and Lachung Rivers have been produced [Figs. 4( $a$ and b)]. Figs. 4( $a$ and b) clearly show that the upstream chainages corresponded to low flows because of less catchment area, and the downstream chainages corresponded to a high amount of flow because of the contribution of flows from upstream chainages.

At the origin point of the Teesta River $(\mathrm{Ch}-0)$, where the river is very shallow with water depth less than $0.3 \mathrm{~m}$, the maximum discharge is recorded around $150-200 \mathrm{~m}^{3} / \mathrm{s}$. Whereas, at the downstream cross-section point (Ch-85419) near to Chungthang gauge (Ch-84373), around $85 \mathrm{~km}$ distance from the origin of the river, the maximum discharge (during monsoon season from June to September) is recorded around $700-800 \mathrm{~m}^{3} / \mathrm{s}$. It also showed several high discharge values $\left(1,000 \mathrm{~m}^{3} / \mathrm{s}\right)$, and the computed river depth is $4.0 \mathrm{~m}$. Similar rating curves were obtained for the Lachung River also where the upstream chainages (e.g., Ch-0 and Ch-366) show the discharge and water depth around $140 \mathrm{~m}^{3} / \mathrm{s}$ and $1.8 \mathrm{~m}$, respectively. The downstream chainages of the Lachung River (e.g., Ch-12969 and Ch-40247) show the computed discharge (during monsoon season) and water level as $250-300 \mathrm{~m}^{3} / \mathrm{s}$ and $3.5 \mathrm{~m}$, respectively [Figs. 4(a and b)]. The Teesta River originates from the extremely high elevation zones thus during the monsoon season, Teesta gets flashy.I In this study, high-order fully hydrodynamic wave approximation method is used.

In Fig. 5(a), the discharge computed from MIKE 11 during the historical time (1991-2005) at both the outlet locations (Ch-84373 and Ch-40247) has been compared with the observed discharge. The results were found to be satisfactory at both the chainages. Figs. 5(b-d) show the time series plots of discharge computed from MIKE 11 at different chainages of the Teesta and Lachung Rivers. These plots show how discharge varies across all the given cross sections in the downstream of the rivers. Figs. 5(b and c) show the upstream and downstream chainage discharge of the Teesta River, respectively. These plots show that the upstream flow ranges between 40 and $80 \mathrm{~m}^{3} / \mathrm{s}$ during lean season, while during monsoon season flow can go up to $80-180 \mathrm{~m}^{3} / \mathrm{s}$. In the downstream of the Teesta River, the discharge varies from 40 to $200 \mathrm{~m}^{3} / \mathrm{s}$ during the lean season, and during monsoon, it varies from 400 to $800 \mathrm{~m}^{3} / \mathrm{s}$. Similarly, Lachung discharge varies from 50 to $150 \mathrm{~m}^{3} / \mathrm{s}$ (during a lean season) to $200-300 \mathrm{~m}^{3} / \mathrm{s}$ (during monsoon season) from upstream to downstream, respectively.

Figs. 6(a and b) show water velocities $(\mathrm{m} / \mathrm{s})$ at various cross sections of the Teesta and Lachung Rivers. Water velocity measurement is necessary because both the rivers originate from extremely hilly terrains, and the whole catchment corresponds to very high-degree slopes. During monsoon season, Teesta gets flashy in nature and high-velocity flood waves travel into the downstream. Fig. 6(a) shows that the maximum average velocity of the Teesta River varies from 1.5 to $8 \mathrm{~m} / \mathrm{s}$, though several extreme velocity events can also be notified (e.g., 9-10 m/s).

At the upstream portion, the maximum velocity of the Teesta River varies around $1.5 \mathrm{~m} / \mathrm{s}$, while in the downstream portion, it varies from 5.5 to $8 \mathrm{~m} / \mathrm{s}$, illustrating high-velocity flow movement in the Teesta River especially in monsoon time. Similarly, in Fig. 6(b), the Lachung River corresponded to water velocity around $0.5-3.8 \mathrm{~m} / \mathrm{s}$. Upstream, the Lachung River corresponded to maximum water velocity around $0.5-1.5 \mathrm{~m} / \mathrm{s}$ while in downstream, it goes up to $3.8 \mathrm{~m} / \mathrm{s}$. However, it is comparatively lower than the Teesta River. Figs. 6(c and d) show the flooded area $\left(\mathrm{m}^{2}\right)$ at each chainage location of the Teesta and Lachung Rivers. Water velocity increases in the downstream as more water is added to rivers via tributary rivers. This means that less of the water is in contact with the bed of the river and the mouth so there is less energy used to overcome friction. Hence, the rivers flow progressively faster on their journey downstream. The flooded area computed from MIKE 11 is based on the given cross sections. Figs. 6(c and d) show a significant variability in the computed flooded area at different downstream chainages of the Teesta and Lachung Rivers.

The effect of climate change on the main hydrodynamic variables, such as water level, flood discharge, and water velocity, is evaluated utilizing CMIP5 CM3 model-based RCP experimental scenarios. The discharge time series is used as a variable parameter in the input boundary conditions. Before that, SWAT has been calibrated and validated at both the outlet locations to reduce the model uncertainty issues in the projected scenarios. A SUFI2-based parameter optimization method has been performed to project the accurate and precise scenarios of streamflow at various gauged and ungauged locations over the catchment.

The SWAT model calibration and uncertainty analysis results in a daily simulation step shown in Table 2 . The objective functions, such as $R^{2}$ and NSE, were used to assess the model performance during the historical time from the 1991 to 2005. The NSE coefficient is computed nearly close to $R^{2}$ during both model calibration and validation for each outlet. The daily basis results are found acceptable, and the computed $R^{2}$ and NSE values are comparable to previous studies (Zhang et al. 2014; Jain et al. 2010; Abbaspour et al. 2007; Gosain et al. 2006). Among both the stations, the Chungthang gauge-based predicted discharge values are well optimized as compared to the observed discharge, as their $R^{2}$ and NSE showed a better correlation than Lachung. This is because the model has been calibrated from upstream (e.g., Lachung) to downstream (e.g., Chungthang). The best computations of the parameters of upstream make limited contributions to the next calibration processes, leading to enhanced simulation results at downstream gauge stations.

Table 2 also provided the results of the SUFI 2 method-based streamflow parameterization sensitivity and uncertainty analysis outcomes. The modeled uncertainties determined through the objective functions, such as p-factor and r-factors, are shown in Table 2. The modeling outcomes show that the simulated data are mostly falling within the uncertainty band (upper 95PPU), as already explained in the methodology section. As per the daily computational outcomes, around 55\% simulated data (in some cases it is more than 60\%) sets are matching with the observed data sets, while as per the monthly basis observations, around 60\% simulated discharge values are matching with the observed data values. The r-factor showed an optimal uncertainty level in the simulated 
discharge. The overall uncertainty evaluation results, using p-factor and r-factor, suggest that the predicted outcomes are fairly optimized and comparable to previous studies (Zhang et al. 2014; Schilling et al. 2008; Abbaspour et al. 2007).
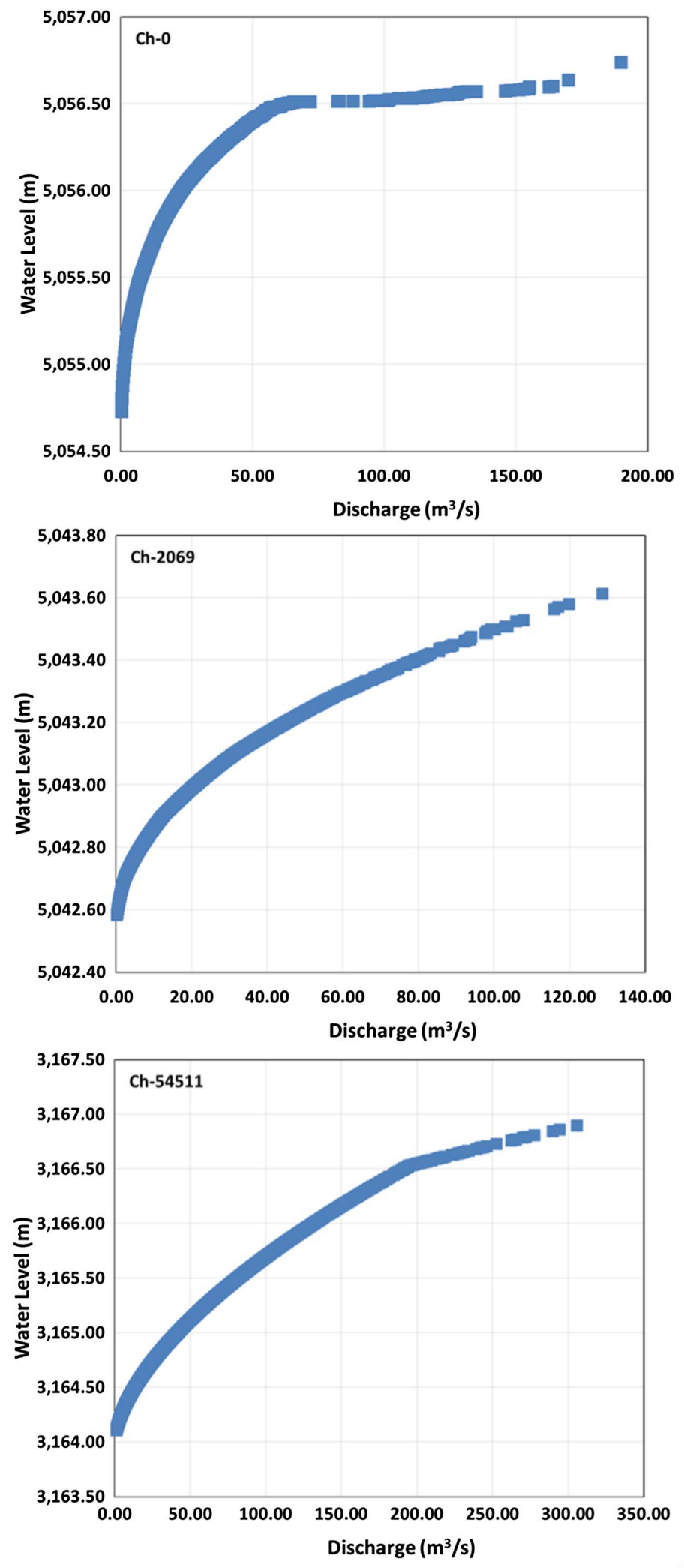

(a)
The sensitivity of the calibrated-validated streamflow parameters (e.g., five parameters are identified as the most relevant parameters to streamflow process in literature survey) was evaluated to overcome the model calibration uncertainty issues. The selection
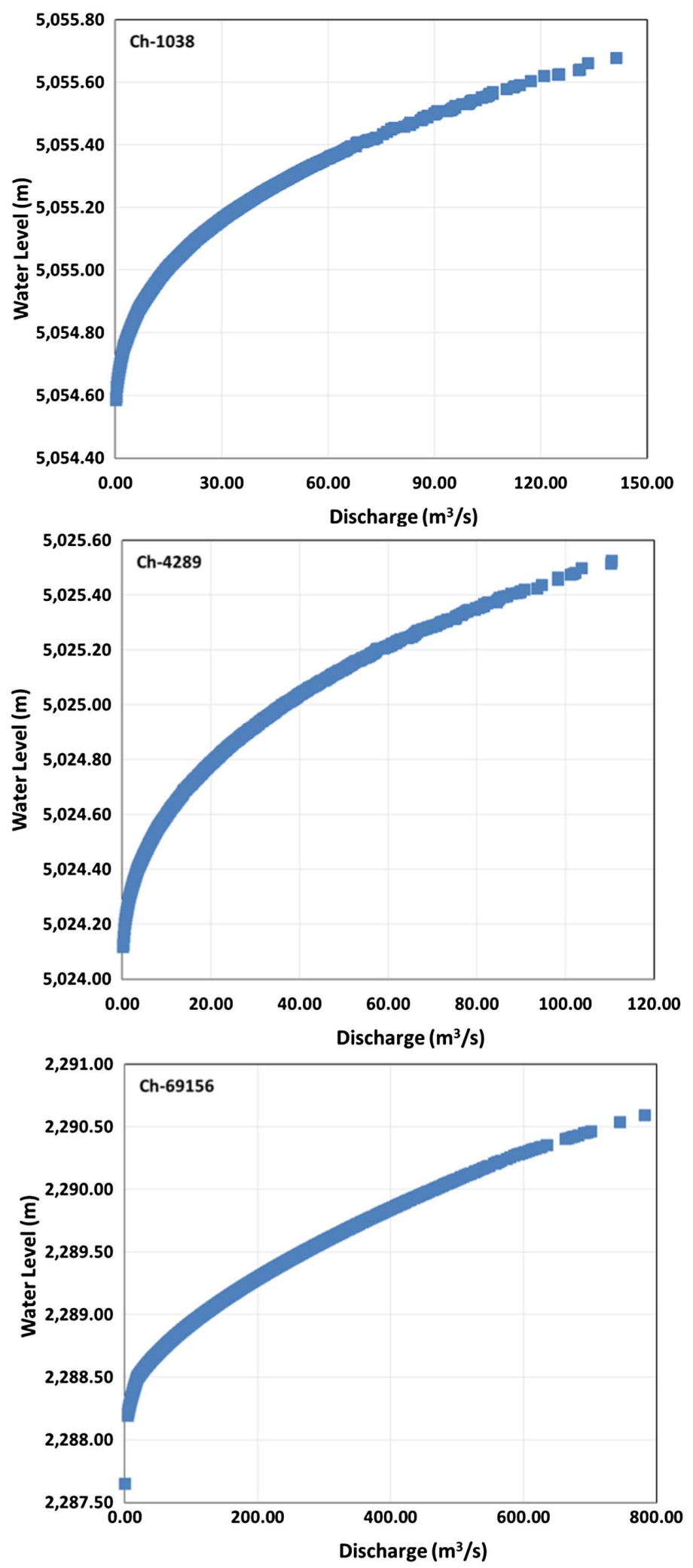

Fig. 4. Stage-discharge relationship or rating curves (RC) at different cross-sectional locations or chainages; (a) RC for the Teesta River; (b) RC for the Lachung River 

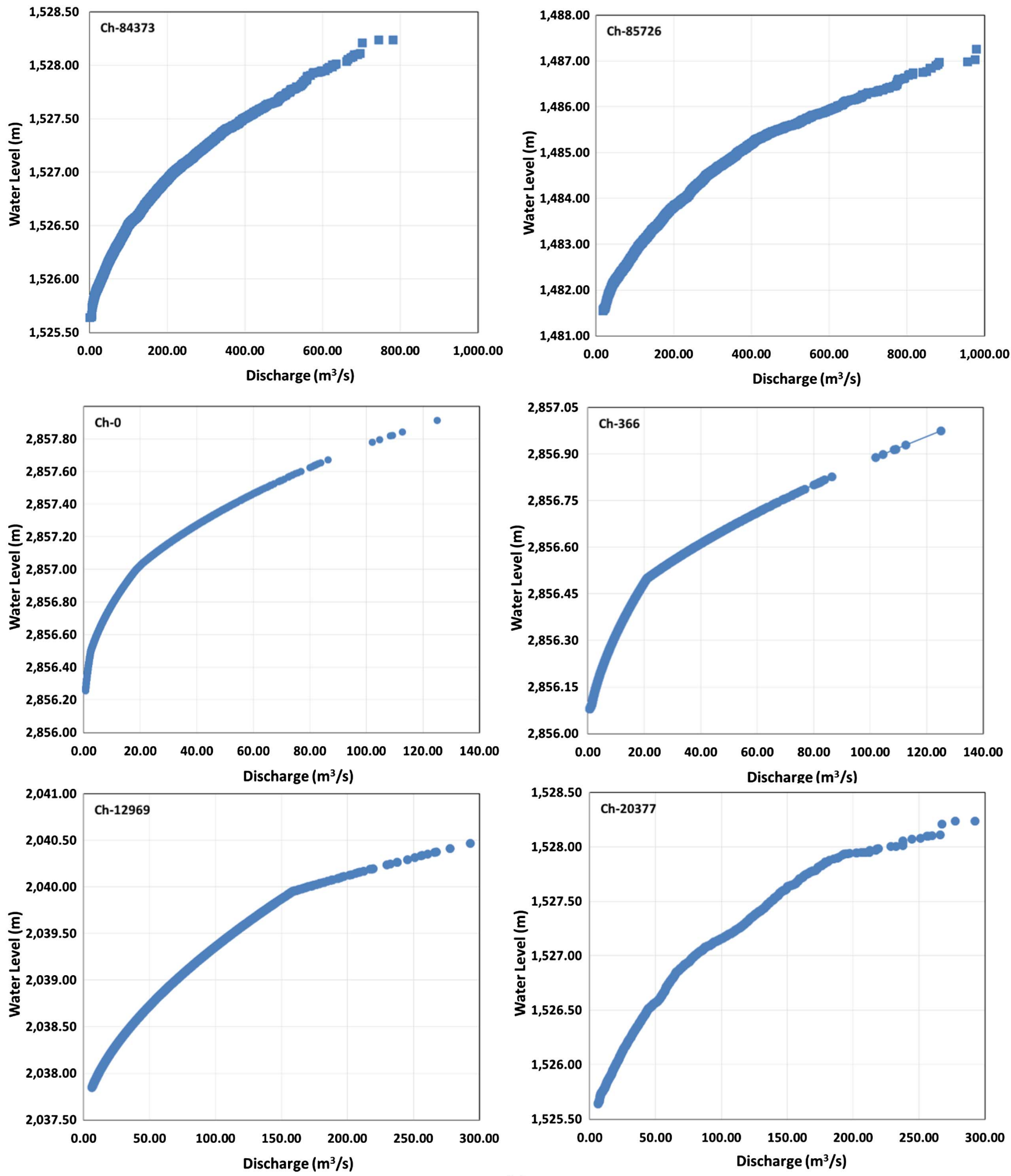

(b)

Fig. 4. (Continued.)

of the most relevant and influencing parameters in the final calibration process improved the accuracy of the modeling outcomes (Table 3). For optimizing best-fitted coefficient value, $R^{2}$ and NSE objective functions were applied. For sensitivity ranking, the statistical significance tests, such as t-stat and p-value, were applied (Singh et al. 2013). The best-fitted parameter coefficients are obtained after performing multiple iterative processes and thus the final fitted best coefficient values were obtained during initial and 


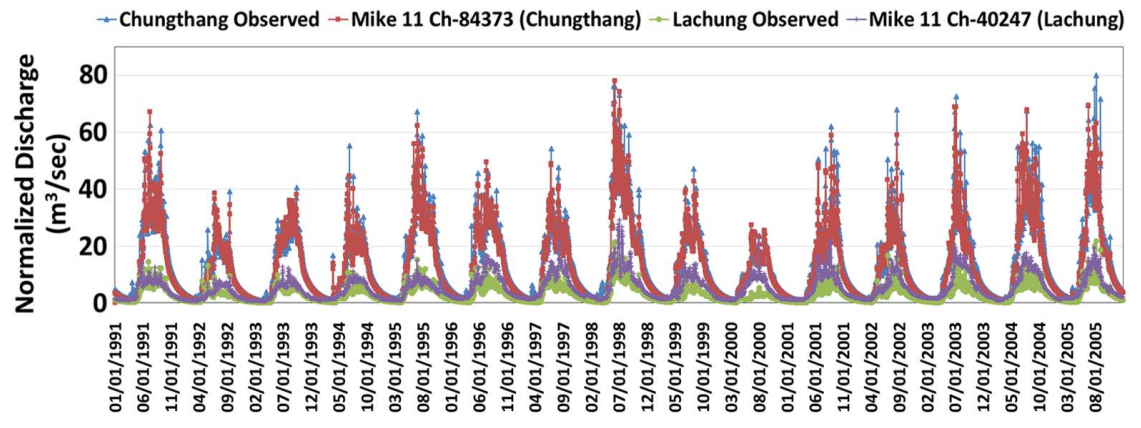

(a)

Time Series (1991-2005)
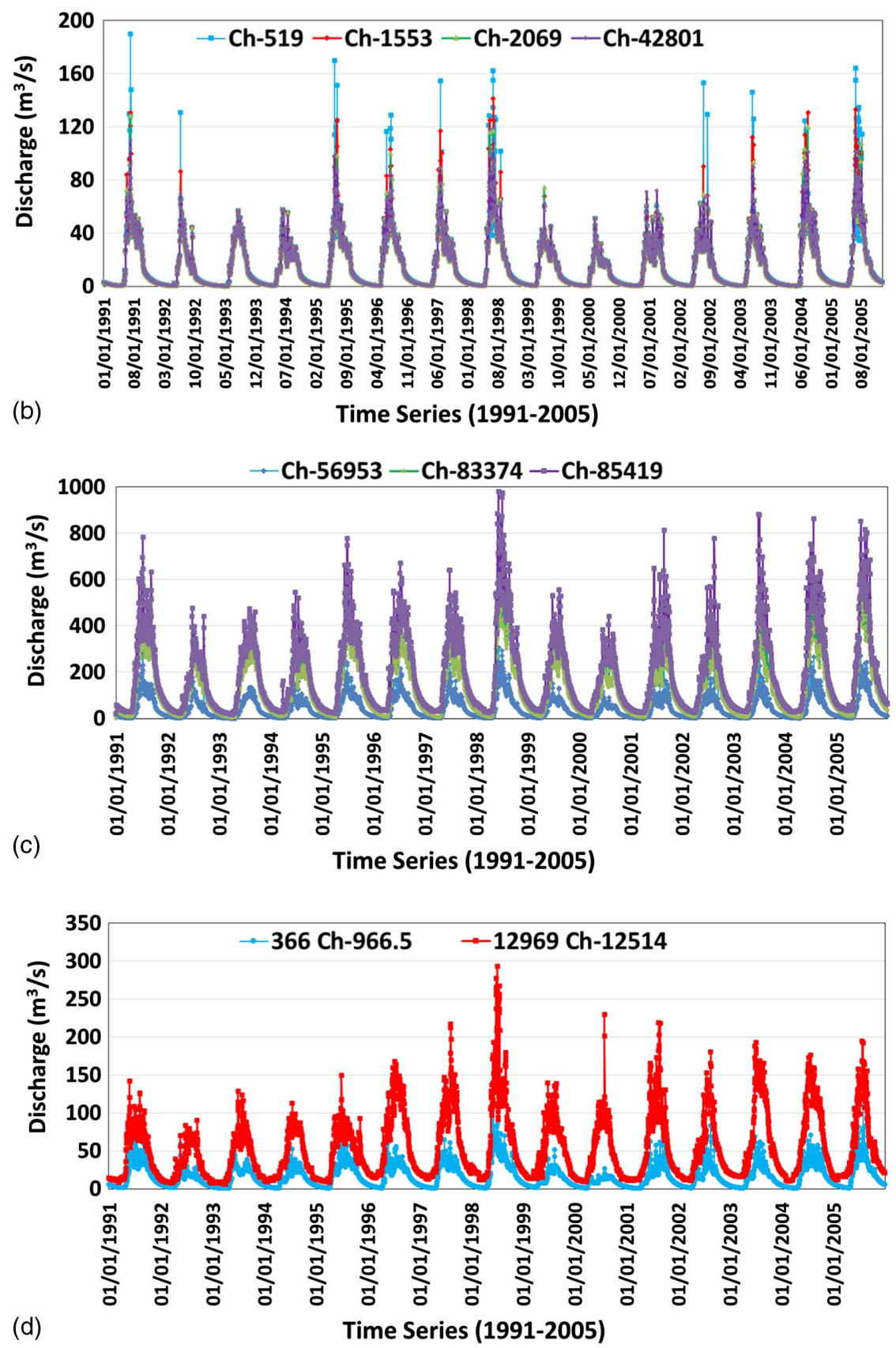

Fig. 5. (a) Comparison of MIKE 11- with reference to both the outlet locations; (b) streamflow discharge at upstream chainages (Ch) of Teesta River; (c) streamflow discharge at downstream chainages of Teesta River; (d) streamflow discharge at upstream and downstream chainages of Lachung River 

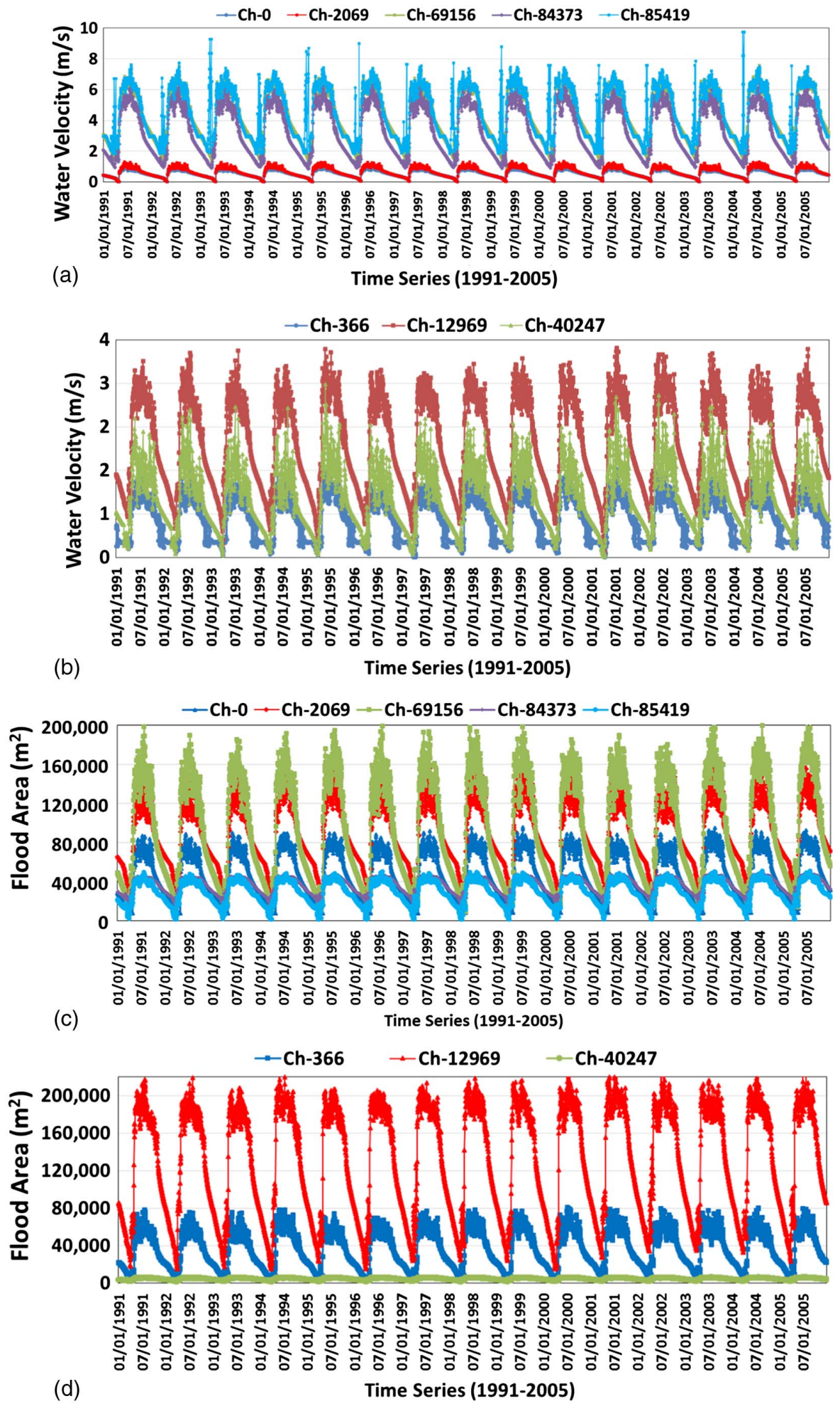

Fig. 6. (a) Water velocities at different chainages of Teesta River; (b) water velocities at different chainages of Lachung River; (c) flooded area at different chainages of Teesta River; (d) flooded area at different chainages of Lachung River

final iterations (Table 3). Among five calibration parameters, three parameters, such as r_CN2, v_GW_DELAY, and r_SOL_K, are computed as the most significant sensitive parameters for the model calibration, whose p-values are recorded almost zero and t-stat values are opted $>+1.96$ or $<-1.96$. These parameters show a significant response in the optimization of best coefficient values.
The resultant flood water level, discharge, and water velocity scenarios (2008-2100), which were generated in MIKE 11 at both the outlet locations (e.g., Lachung and Chungthang) are shown in Fig. 7. Fig. 7(a) shows the projection of water level. In Fig. 7(a), one can observe an increase in the water level during the monsoon season in the given time series except July. In July, it shows a slight decrease in the water level. Among all the monsoon months, 
Table 3. Sensitivity Results as per SUFI2 on a Daily Basis Analysis

\begin{tabular}{|c|c|c|c|c|c|c|c|c|c|}
\hline \multirow[b]{2}{*}{ Parameters } & \multirow[b]{2}{*}{ Parameter name } & \multicolumn{3}{|c|}{ First iteration } & \multicolumn{3}{|c|}{ Final iteration } & \multicolumn{2}{|c|}{ Sensitivity results } \\
\hline & & $\begin{array}{l}\text { Minimum } \\
\text { value }\end{array}$ & $\begin{array}{l}\text { Maximum } \\
\text { value }\end{array}$ & $\begin{array}{l}\text { Fitted } \\
\text { value }\end{array}$ & $\begin{array}{l}\text { Minimum } \\
\text { value }\end{array}$ & $\begin{array}{l}\text { Maximum } \\
\text { value }\end{array}$ & $\begin{array}{l}\text { Fitted } \\
\text { value }\end{array}$ & t-stat & $p$-value \\
\hline Curve number coefficient & $\mathrm{R} \_\mathrm{CN} 2 . \mathrm{mgt}$ & -0.2 & 0.2 & -0.02 & -0.03 & 0.10 & 0.01 & -6.869 & 0 \\
\hline Baseflow alfa factor coefficient & V_ALPHA_BF.gw & 0.0 & 0.3 & 0.14 & 0.173 & 0.257 & 0.18 & -1.562 & 0.119 \\
\hline Groundwater delay time & V_GW_DELAY.gw & 10 & 450 & 15.13 & 2 & 27.19 & 14.67 & -4.812 & 0 \\
\hline Soil hydraulic conductivity & R_SOL_K.sol & N/A & N/A & N/A & -0.04 & -0.84 & -0.81 & 1.96 & 0.045 \\
\hline Slope fraction at HRU & R_HRU_SLP.hru & N/A & N/A & N/A & -0.02 & 0.03 & 0.02 & -1.95 & 0.52 \\
\hline
\end{tabular}

\section{Chungthang}
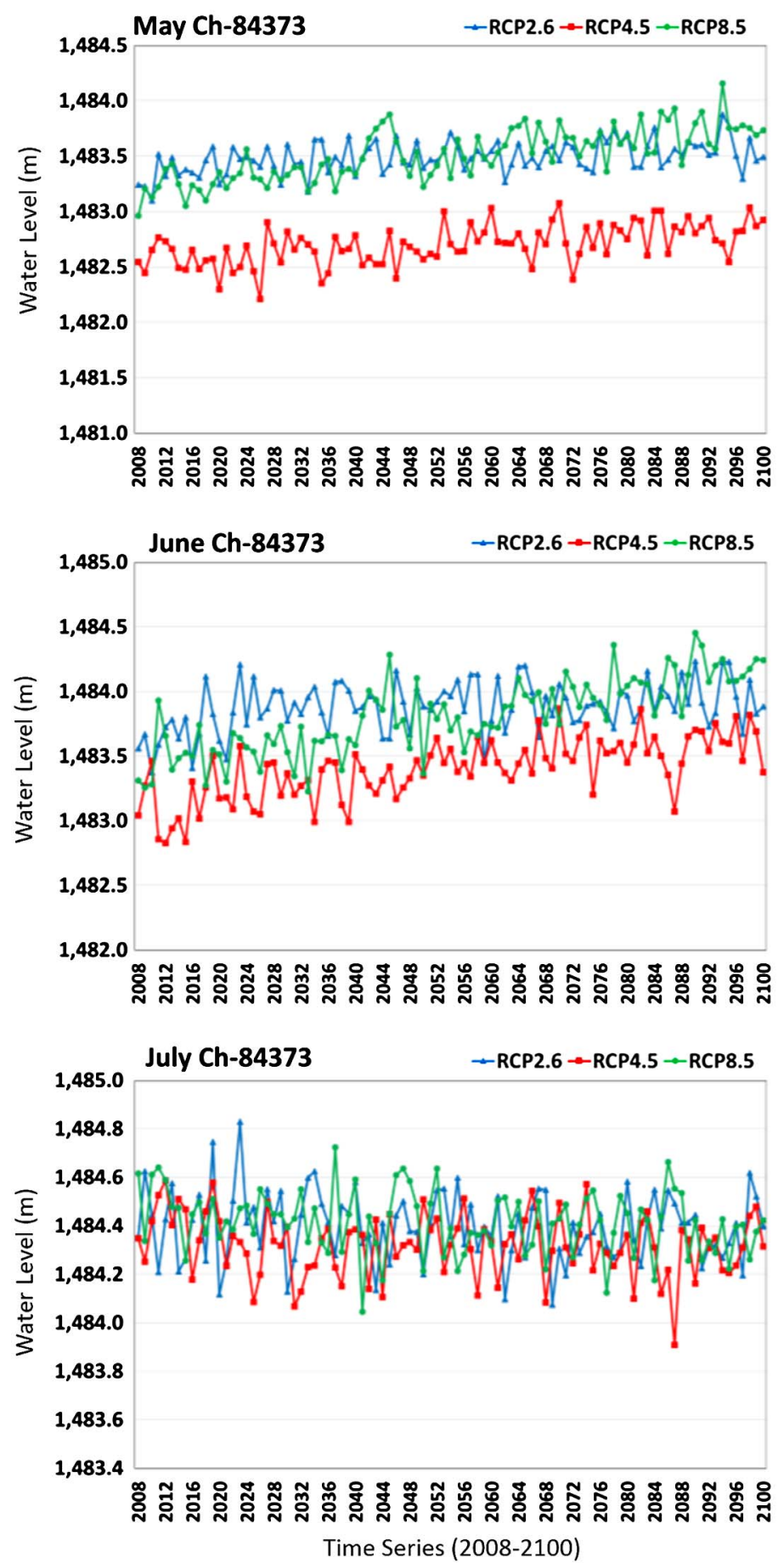

\section{Lachung}
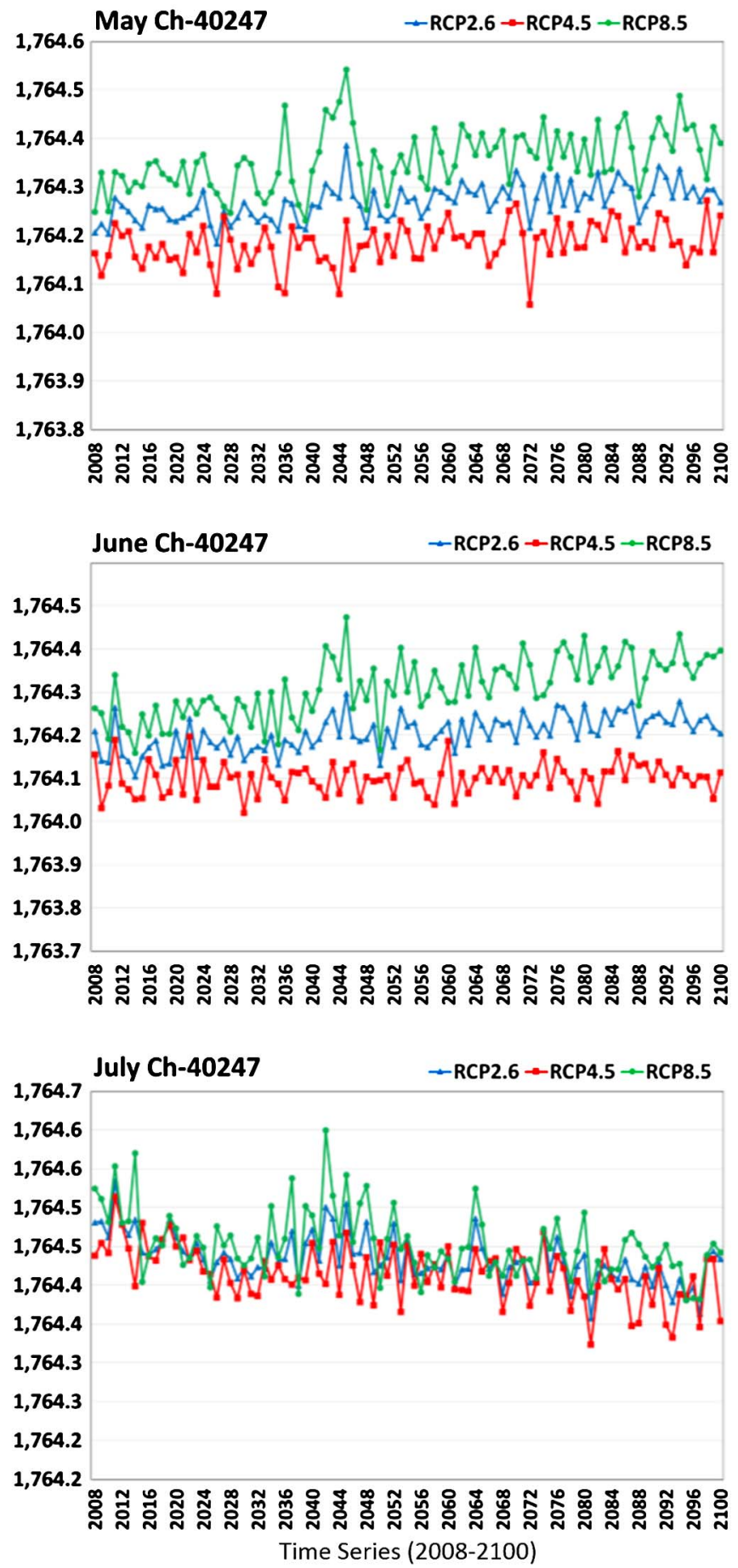

Fig. 7. Projected scenarios of monthly (monsoon durations): (a) water level; (b) discharge; (c) water velocities at both the catchment outlet locations, such as Chungthang and Lachung, using CMIP5 CM3 GCMs during the years 2008-2100 
Chungthang
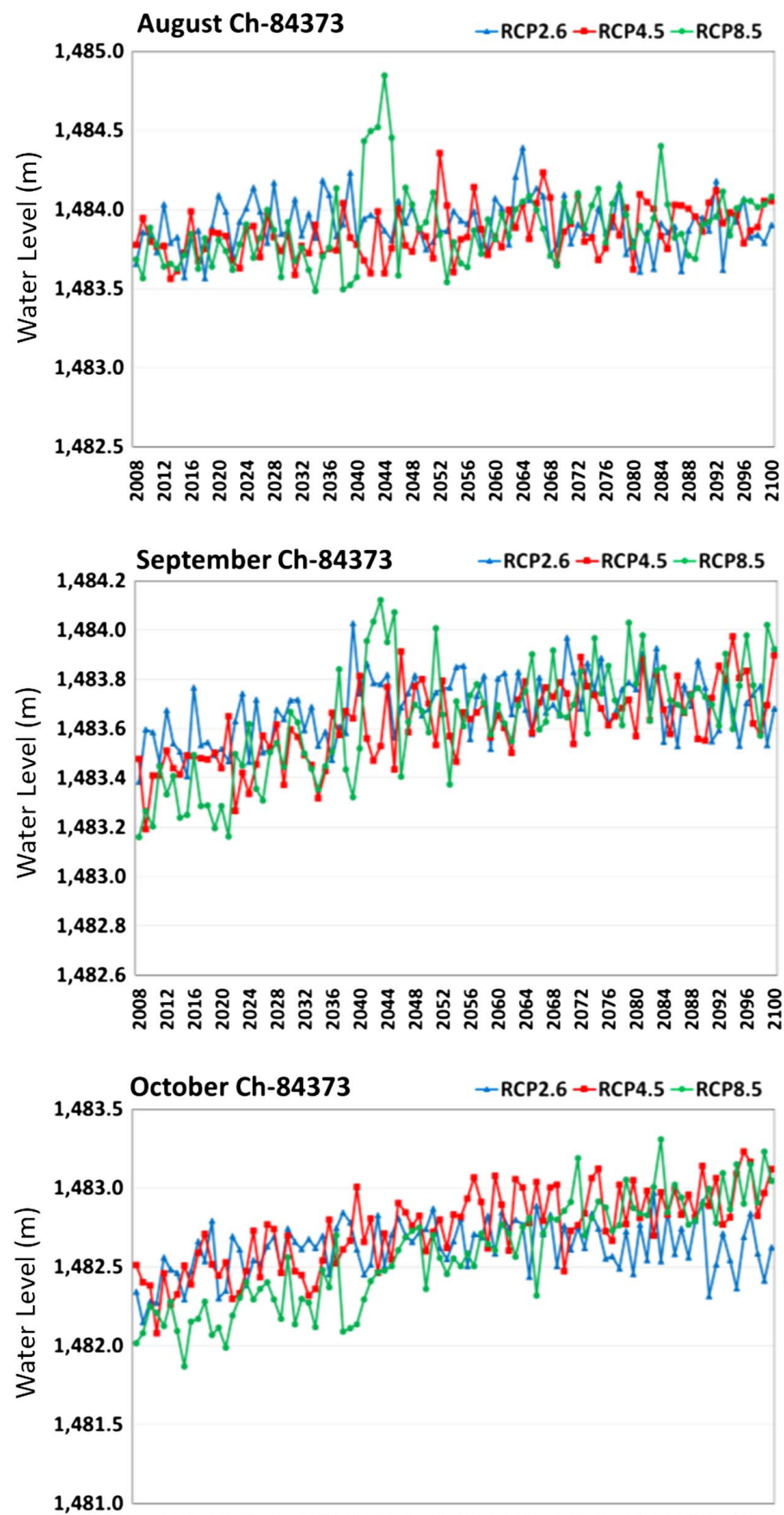

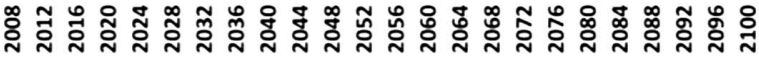

Time Series (2008-2100)
Lachung

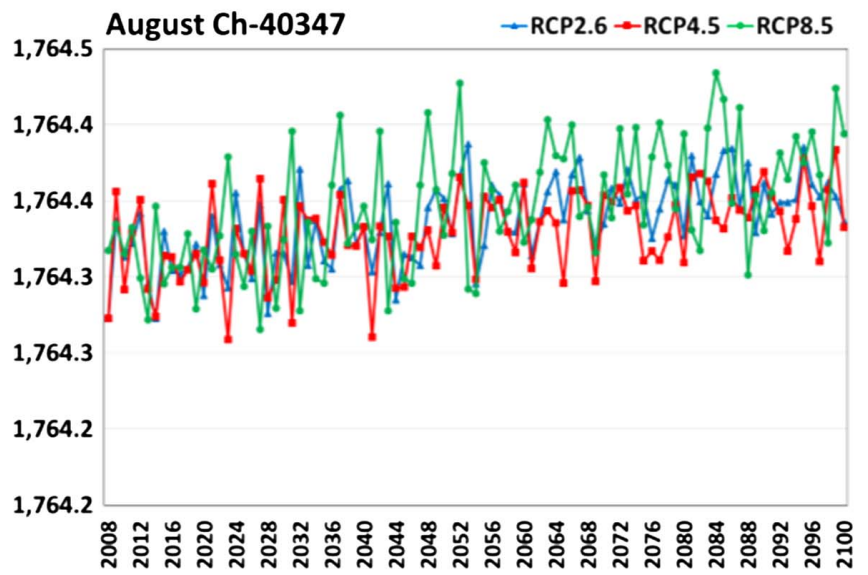

September Ch-40373 $\rightarrow$ RCP2.6 $\rightarrow$ RCP4.5 $\rightarrow$ RCP8.5
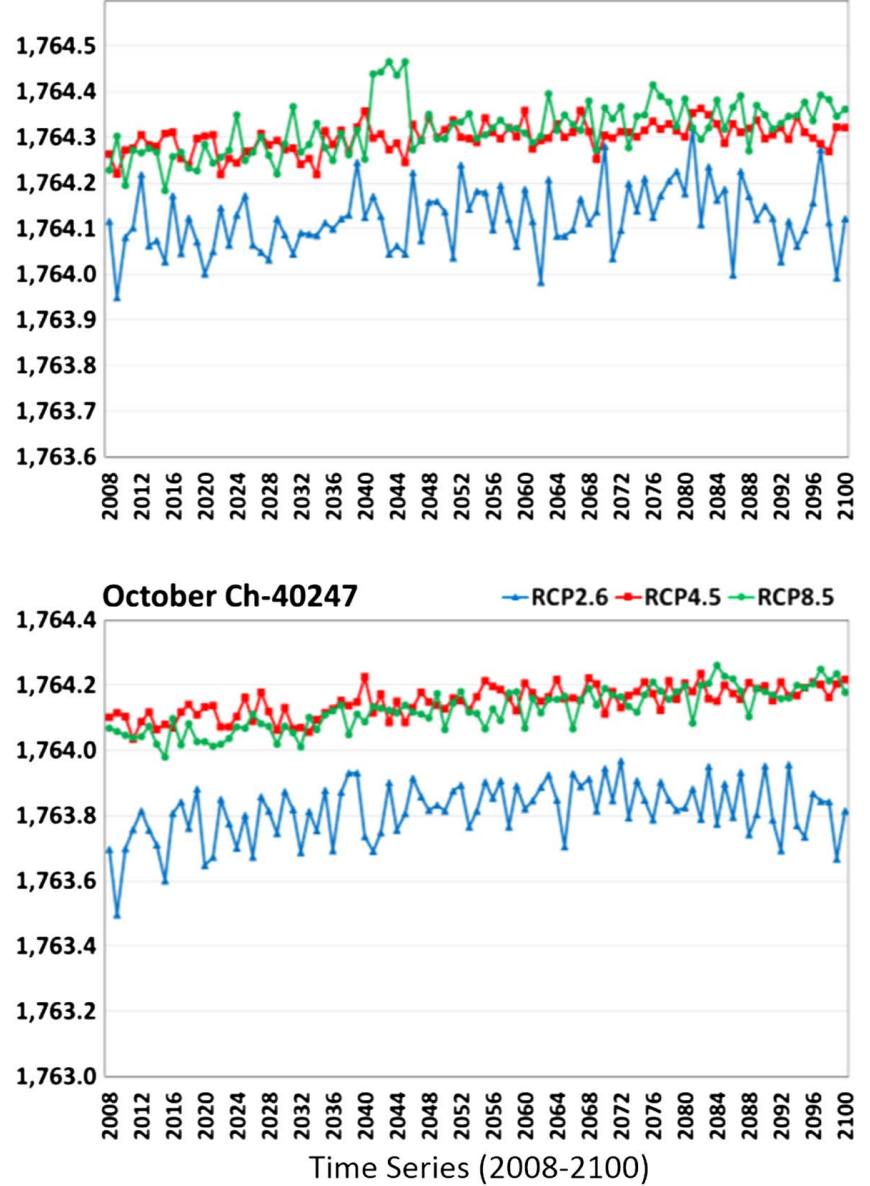

(a)

Fig. 7. (Continued.)

August has shown a consistent increase in the water level. In the projected scenarios of water level, several uneven extreme events can also be identified in the time series plots. Fig. 7(b) shows the projected scenarios of discharge during the monsoon period. In the projected time series, a consistent increase in the discharge amount is observed across all the months except July.

As per the comparison between observed [Figs. 5(b-d)] and projected scenarios [Fig. 7(a)], at the Chungthang outlet, it showed a large variation in the future discharge amount. In the projected discharge, the amount of discharge has been increased, and it ranged from 1,200 to $1,400 \mathrm{~m}^{3} / \mathrm{s}$, illustrating an extreme flow movement in the downstream of the Teesta River. MIKE 11 shows very noteworthy projection scenarios of discharge and other variables. Apart from a consistent increase that has been observed in the maximum peak (2008-2100), the amount of discharge is also increased during the projected time (2008-2100). Among all the RCPs, the extreme emission scenario (RCP8.5) shows maximum increments in the future discharge values. Fig. 7(c) shows the future projected monthwise (monsoon period) water velocities at both the chainages. Fig. 7(c) clearly shows that the water velocity will be 
Chungthang
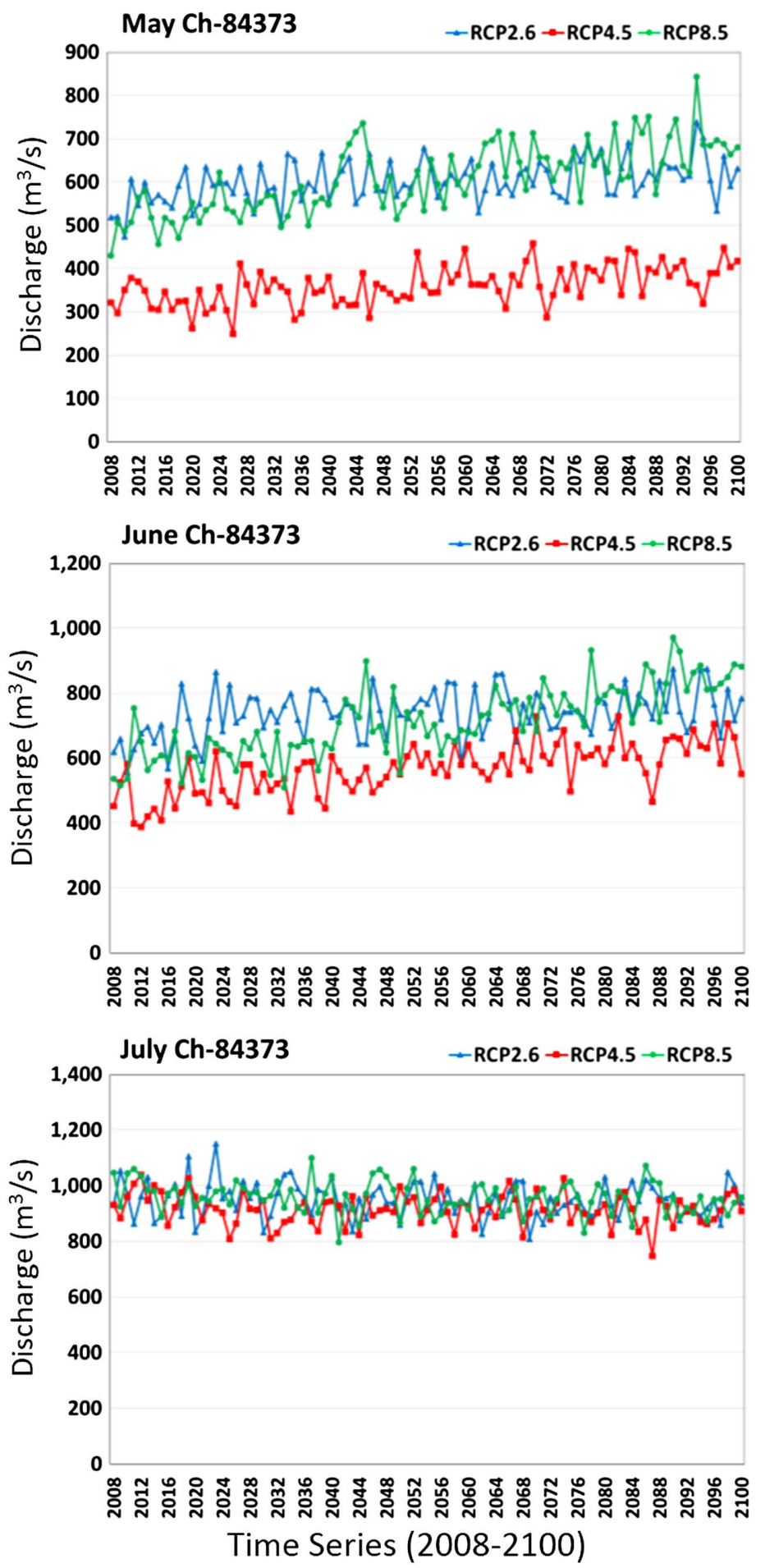

Lachung
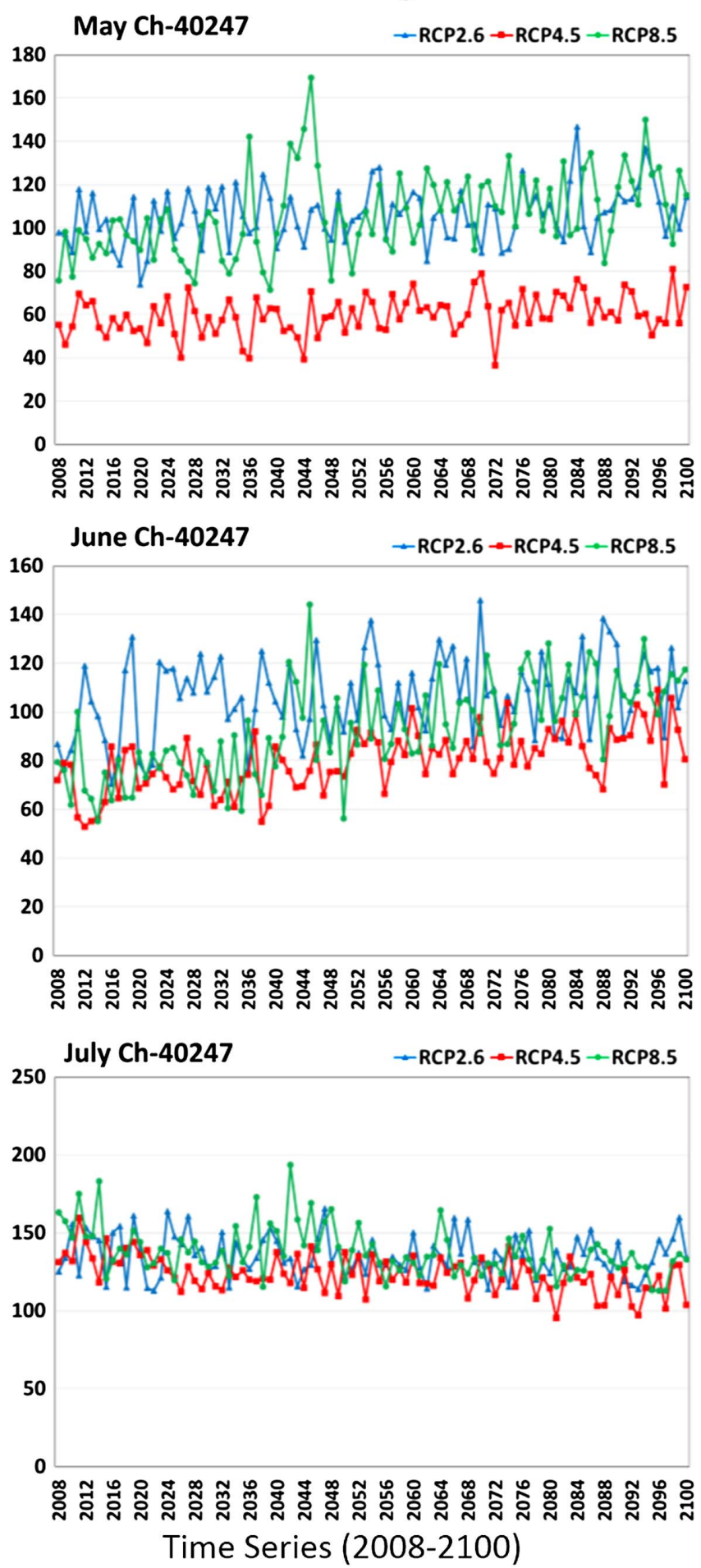

Fig. 7. (Continued.)

increased in the 21st century over the Teesta and Lachung Rivers. At Teesta River, the maximum water velocities vary from 6.5 to $8 \mathrm{~m} / \mathrm{s}$, while at Lachung River it varies from 1.7 to $3 \mathrm{~m} / \mathrm{s}$ during monsoon months. In the time series plots of projected water velocities, a consistent increasing trend has been observed, illustrating that if the discharge volume will be increased, then the water velocity will also be increased.

There are various kinds of functions that can be used for fitting the rating curves or stage-discharge relationship and extrapolation.
A polynomial of second and third degree is commonly used (Rahman et al. 2011) and is used in this study. Based on the projected water level $(h)$ and discharge $(Q)$, under the CMIP5 CM3 GCMs with multiple RCP experiments (RCP2.6, RCP4.5, and RCP8.5), the rating curve equations (stage-discharge relationships) have been developed using logarithmic method (Rahman et al. 2011) (Table 4). During high velocity and amount of flows or high stages, computational conditions tender serious practical complications, thus it is often necessary to extend the rating curve 
Chungthang
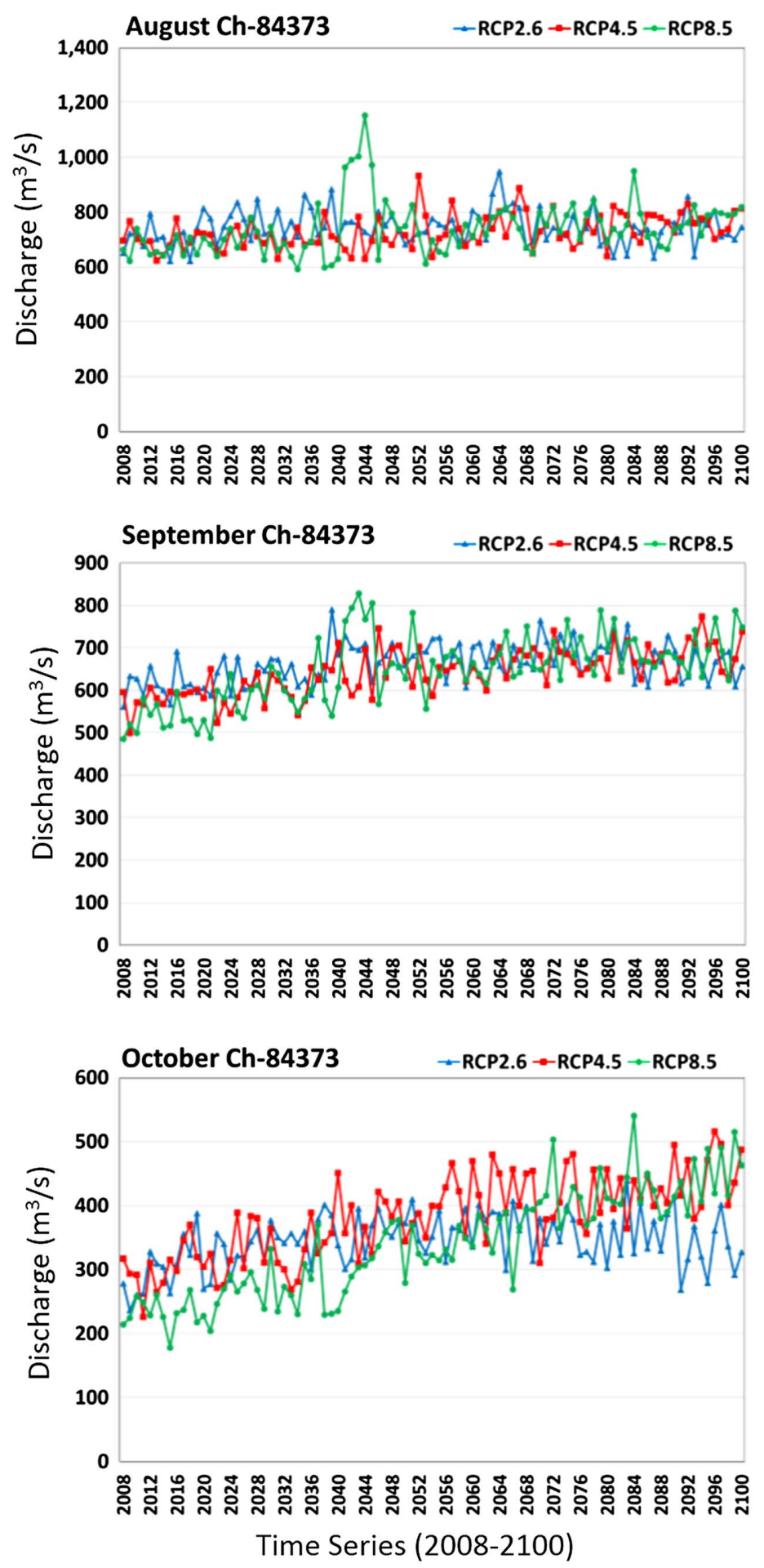

\section{Lachung}

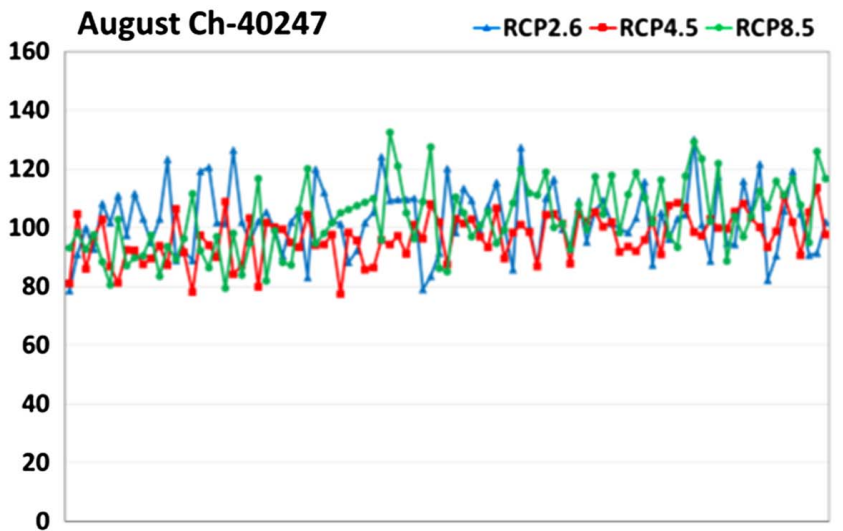

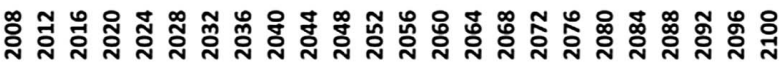

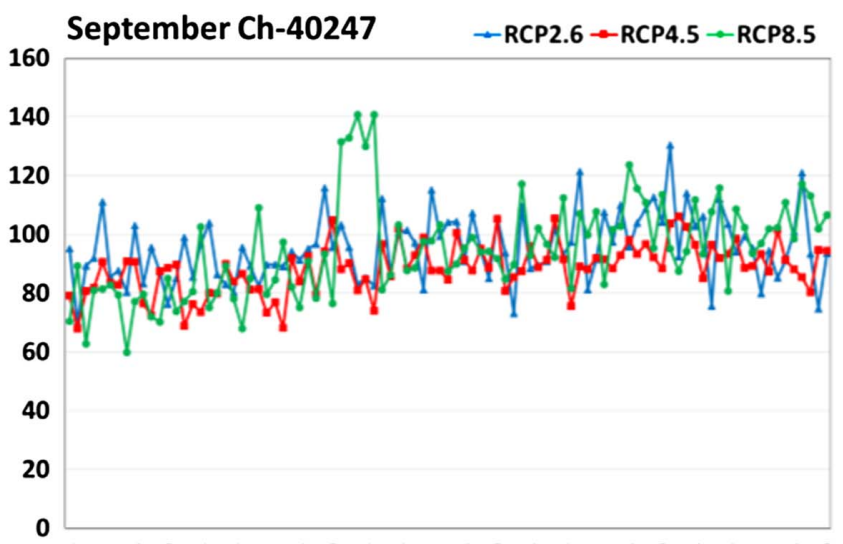

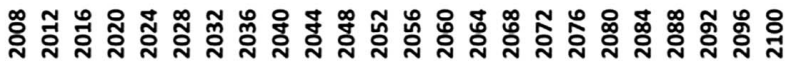

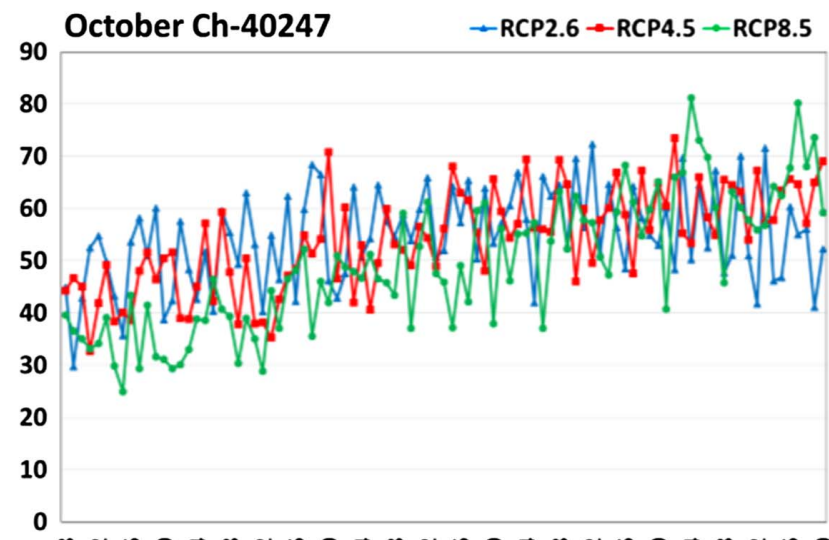

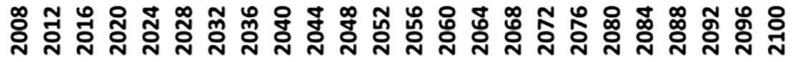
Time Series (2008-2100)

(b)

Fig. 7. (Continued.)

beyond the measured highest discharges. The logarithmic plot method performs well in extrapolating the flow corresponding to high and low stages. For the development of the rating curve equations, around 93 years monthly discharge and water level data sets were considered under RCP experiments generated in SWAT and MIKE 11. The rating curve equation previously developed by Mosley and McKercher (1993) has been considered for the development of the rating curve equations as given

$$
Q=C\left(h-Z_{0}\right)^{n}
$$

where $Q=$ discharge $\left(\mathrm{m}^{3} / \mathrm{s}\right) ; C$ and $n=$ constants; $h=$ water level or height (m); and $Z_{0}=$ height at which discharge is zero. Values of $n$ and $C$ have been determined as the calibration parameter. The value of $n$ varies with cross-section shape, from 1.67 for a rectangular section up to 2.67 for a triangular section (Rahman et al. 2011).

As per a literature survey, natural channels are generally parabolic in cross section. Therefore, in this study $n$ equal to 2 is 
Chungthang
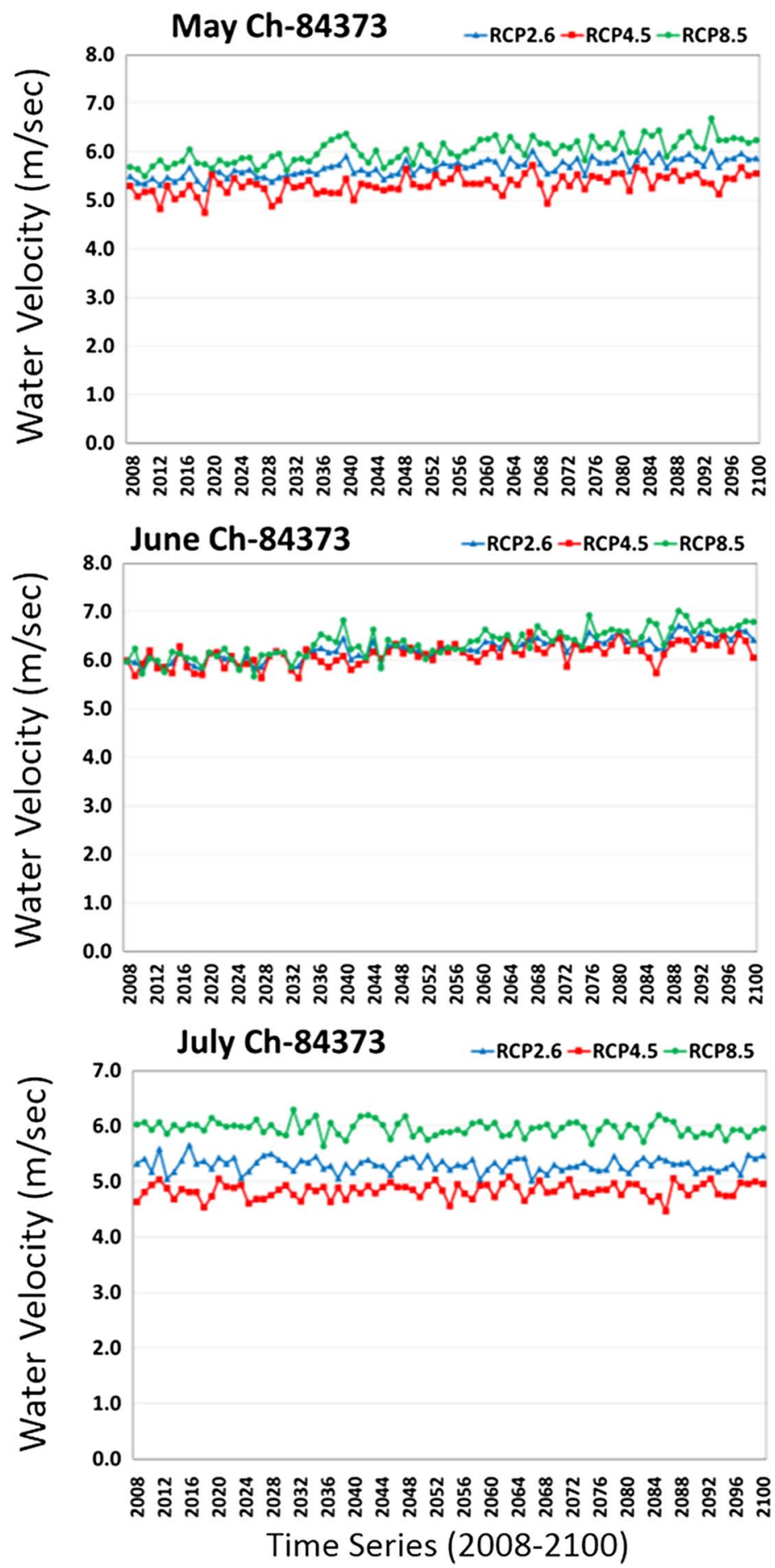

Lachung
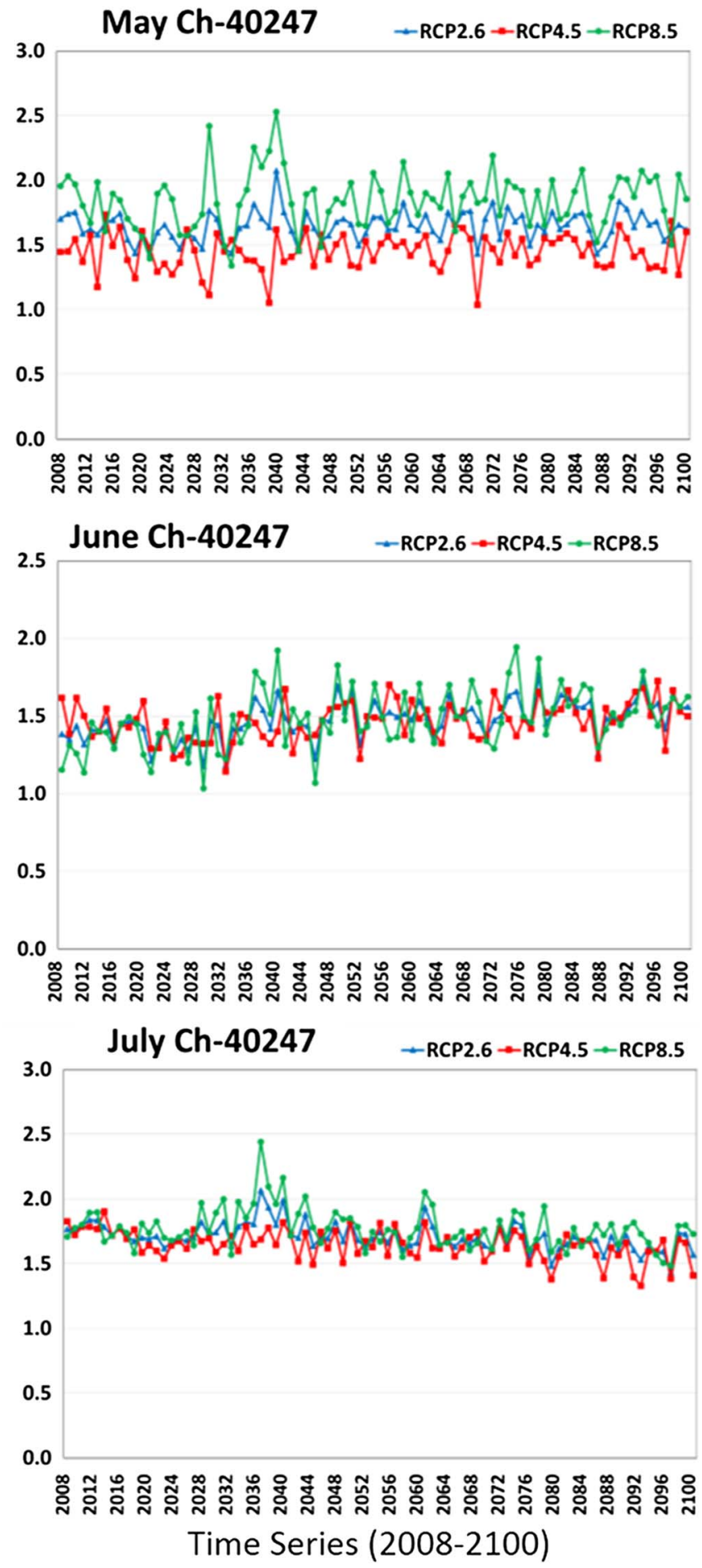

Fig. 7. (Continued.)

considered for the optimization. The statistical evaluation method, such as $R^{2}$, was considered for evaluation of predicted discharge and projected discharge. The $R^{2}$ is obtained greater than 0.85 in all the equations. The newly developed rating curve equations have been shown in Table 4. Using these rating curve equations at both the gauges i.e., Chungthang and Lachung, the flood stages and return periods can be computed for the 21 st century in climate extreme conditions.

\section{Conclusions}

The Teesta River originates from the Indian Himalayan terrains, which contributes a significant amount of discharge during monsoon season, making it vulnerable to flood events with different extents and magnitudes almost every year. The present study demonstrated the utility of a hydrological model SWAT and a hydraulic unsteady flow model MIKE 11 in the computation of discharge, 


\section{Chungthang}
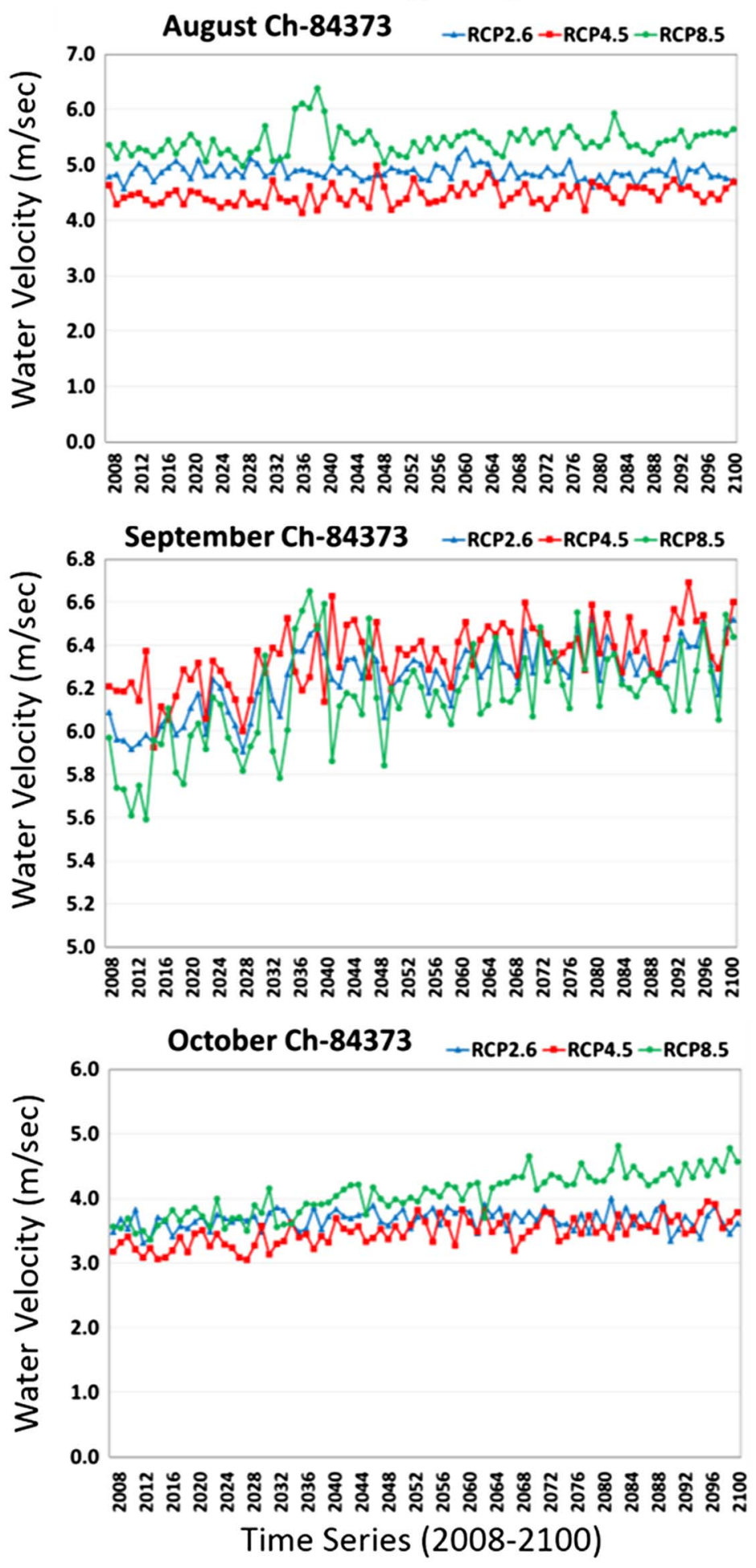

Lachung
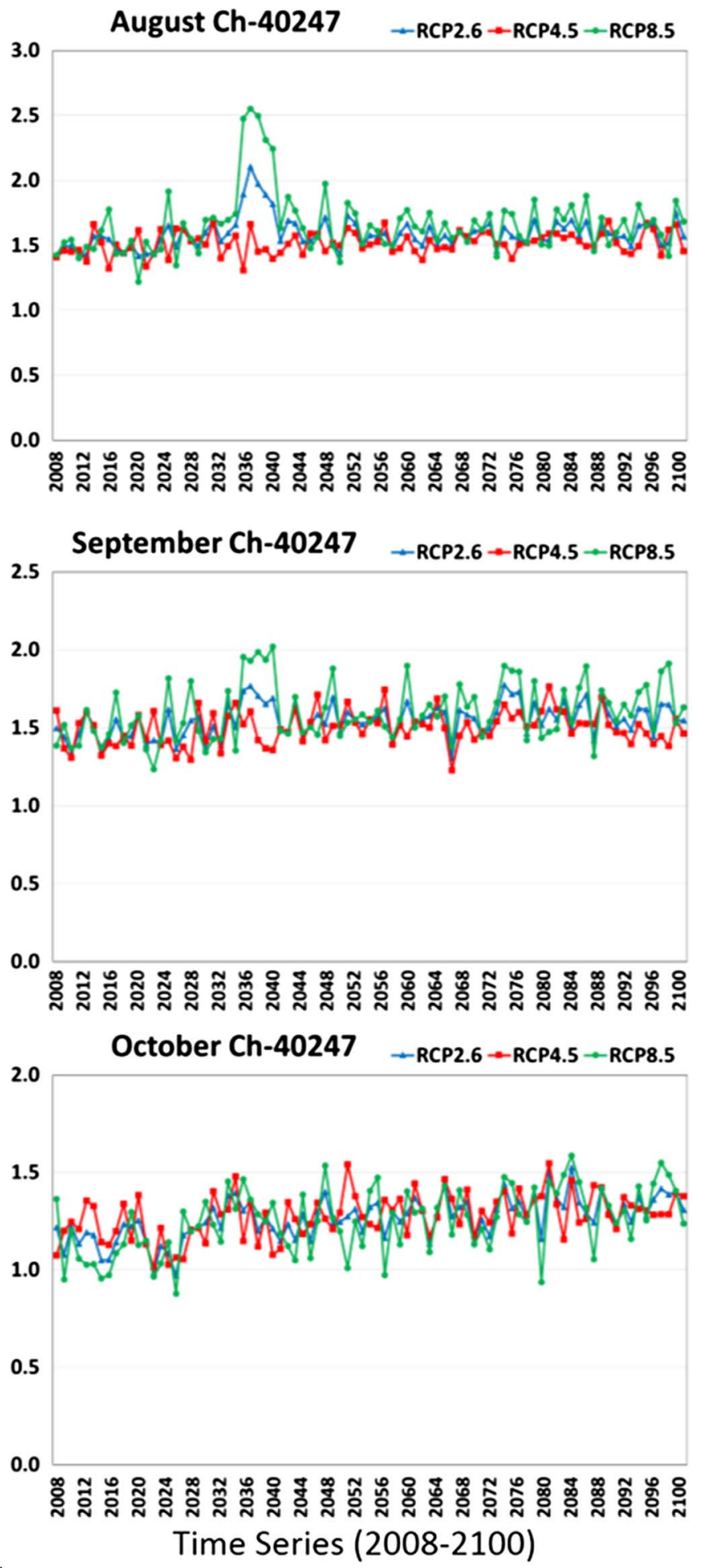

(c)

Fig. 7. (Continued.)

water level, and water velocities in the historical and future time series domain. For the projection of futuristic scenarios of water velocities and discharge at various river cross sections, the SWAT model is coupled with MIKE 11 under the latest CMIP5 CM3 GCMs. A current and futuristic computation and projection of unsteady river flow and stage can be helpful in the ongoing and proposed water resource projects, such as hydropower projects, flood mitigation, and the establishment of drinking water projects. The latest CMIP5 CM3 GCMs were significantly used in assessing the current and futuristic climate change impacts on the downstream river flow of Teesta and Lachung Rivers. The development of rating curve equations based on the downscaled stage and discharge data sets can be effectively used to analyze the future response of streamflows under the extreme events. The simulated 
Table 4. Development of Rating Curve Equation Using Projected Future Water Level and Discharge (2008-2100)

\begin{tabular}{|c|c|c|c|}
\hline \multirow[b]{2}{*}{ RCPs-CM3 (2008-2100) } & \multirow{2}{*}{$\begin{array}{l}\text { Q-h equation/optimization } \\
\text { coefficients }^{\mathrm{a}}\end{array}$} & \multicolumn{2}{|c|}{ Cross sections/chainages } \\
\hline & & 86,465 (Chungthang) & 20,118 (Lachung) \\
\hline CM3RCP2.6 & $\begin{array}{c}\mathrm{C}^{\mathrm{a}} \\
\mathrm{n}^{\mathrm{a}} \\
Z_{0}(\text { where } Q=0)\end{array}$ & $\begin{array}{l}256.992 \\
1.769 \\
0.098\end{array}$ & $\begin{array}{c}139.184 \\
1.13 \\
0.09\end{array}$ \\
\hline CM3RCP4.5 & $\begin{array}{c}Q=C\left(h-Z_{0}\right)^{\hat{n}} \\
\mathrm{C}^{\mathrm{a}} \\
\mathrm{n}^{\mathrm{a}} \\
Z_{0}(\text { where } Q=0) \\
Q=C\left(h-Z_{0}\right)_{\hat{n}}\end{array}$ & $\begin{array}{c}Q=256.992(h-0.098)^{\hat{1} .796} \\
289.667 \\
0.0826 \\
0.095 \\
Q=289.667(h-0.0826)^{\hat{0} .0826}\end{array}$ & $\begin{array}{c}Q=139.184(h-0.09)^{\hat{1} .13} \\
143.627 \\
0.661 \\
0.028 \\
Q=143.627(h-0.028)^{\hat{0} .661}\end{array}$ \\
\hline CM3RCP8.5 & $\begin{array}{c}\mathrm{C}^{\mathrm{a}} \\
\mathrm{N}^{\mathrm{a}} \\
Z_{0}(\text { where } Q=0) \\
Q=C\left(h-Z_{0}\right)^{\hat{n}}\end{array}$ & $\begin{array}{c}361.7763 \\
0.971 \\
0.11 \\
Q=361.7763(h-0.11)^{0.971}\end{array}$ & $\begin{array}{c}288.9974 \\
1.228 \\
0.069 \\
Q=288.997(h-0.069)^{\hat{1} .228}\end{array}$ \\
\hline
\end{tabular}

${ }^{\mathrm{a} C}$ Coefficients.

streamflow computed from the model was calibrated and validated with the observed/measured streamflow, and modeling results were found well matching with the observed data.

\section{Acknowledgments}

This research work has been carried out under DST research project No. SB/DGH-66/2013, and financial support is gratefully acknowledged. We also thank GFDL, New Jersey USA, Earth Explorer NASA, CWC New Delhi India, IMD Pune India, and IITM Pune India for providing the required data sets for the completion of this research work.

\section{Supplemental Data}

Table S1, the modified CN table, is available online in the ASCE Library (www.ascelibrary.org).

\section{References}

Abbaspour, K. C. (2011). "SWAT-CUP4: SWAT calibration and uncertainty programs-A user manual." Swiss Federal Institute of Aquatic Science and Technology, Dübendorf, Switzerland.

Abbaspour, K. C., et al. (2007). "Modelling hydrology and water quality in the pre-alpine/alpine Thur watershed using SWAT." J. Hydrol., 333(2-4), 413-430.

Arnold, J. G., et al. (2012). "SWAT." Trans. ASABE, 55(4), 1491-1508.

Change, I. C. (2013). "The physical science basis." Working Group I Contribution to the Fifth Assessment Rep., Intergovernmental Panel on Climate Change, New York.

DHI (Danish Hydraulic Institute). (2004). "MIKE 11 user and reference manual." Hørsholm, Denmark.

Doulgeris, C., Georgiou, P., Papadimos, D., and Papamichail, D. (2012). "Ecosystem approach to water resources management using the MIKE 11 modeling system in the Strymonas River and Lake Kerkini." J. Environ. Manage, 94(1), 132-143.

Escurrat, J. J., Vazquez, V., Cestti, R., De Nys, E., and Srinivasan, R. (2014). "Climate change impact on countrywide water balance in Bolivia." Reg. Environ. Change, 14(2), 727-742.

Ficklin, D. L., and Barnhart, B. L. (2014). "SWAT hydrologic model parameter uncertainty and its implications for hydroclimatic projections in snowmelt-dependent watersheds." J. Hydrol., 519, 2081-2090.

Gardner, A. S., et al. (2009). "Near-surface temperature lapse rates over Arctic glaciers and their implications for temperature downscaling." J. Climate, 22(16), 4281-4298.
Gosain, A. K., Rao, S., and Basuray, D. (2006). "Climate change impact assessment on hydrology of Indian river basins." Curr. Sci., 90(3), 346-353.

Goyal, M. K. (2014). "Modeling of sediment yield prediction using M5 model tree algorithm and wavelet regression." Water Resour. Manage., 28(7), 1991-2003.

Goyal, M. K., and Ojha, C. S. P. (2010). "Robust weighted regression as a down-scaling tool in temperature projections." Int. J. Global Warming, 2(3), 234-251.

Huang, M., Gallichand, J., Wang, Z., and Goulet, M. (2006). "A modification to the soil conservation service curve number method for steep slopes in the Loess Plateau of China." Hydrol. Processes, 20(3), 579-589.

Jain, S. K., Tyagi, J., and Singh, V. (2010). "Simulation of runoff and sediment yield for a Himalayan watershed using SWAT model." J. Water Resour. Prot., 2(3), 267-281.

Karahan, H., Gurarslan, G., and Geem, Z. W. (2013). "Parameter estimation of the nonlinear Muskingum flood-routing model using a hybrid harmony search algorithm." J. Hydrol. Eng., 10.1061/(ASCE)HE .1943-5584.0000608, 352-360.

Kharin, V. V., Zwiers, F. W., Zhang, X., and Wehner, M. (2013). "Changes in temperature and precipitation extremes in the CMIP5 ensemble." Clim. Change, 119(2), 345-357.

Krishna, A. P. (2005). "Snow and glacier cover assessment in the high mountains of Sikkim Himalaya." Hydrol. Processes, 19(12), 2375-2383.

Mahmood, R., and Babel, M. S. (2013). "Evaluation of SDSM developed by annual and monthly sub-models for downscaling temperature and precipitation in the Jhelum basin, Pakistan and India." Theor. Appl. Climatol., 113(1-2), 27-44.

Mike 11 [Computer software]. Danish Hydraulic Institute, Hørsholm, Denmark.

Mishra, S. K., Chaudhary, A., Shrestha, R. K., Pandey, A., and Lal, M. (2014). "Experimental verification of the effect of slope and land use on SCS runoff curve number." Water Resour. Manage., 28(11), 3407-3416.

Mosley, M. P., and McKercher, A. I. (1993). Streamflow. p. 8.1-8.39. Handbook of hydrology, McGraw-Hill, New York.

Nash, J. E., and Sutcliffe, J. V. (1970). "River flow forecasting through conceptual models. Part I-A discussion of principles." J. Hydrol., 10(3), 282-290.

Neitsch, S. L., Arnold, J. G., Kiniri, J. R., and Williams, J. R. (2011). "Soil water assessment tool theoretical documentation version 9." Texas Water Resource Institute of Technical Rep. No. 406, Texas A\&M Univ., College Station, TX.

Patro, S., Chatterjee, C., Singh, R., and Raghuwanshi, N. S. (2009). "Hydrodynamic modelling of a large flood-prone river system in India with limited data." Hydrol. Processes, 23(19), 2774-2791. 
Rahman, M. M., Arya, D. S., Goel, N. K., and Dhamy, A. P. (2011). "Design flow and stage computations in the Teesta River, Bangladesh, using frequency analysis and MIKE 11 modeling." J. Hydrol. Eng., 10.1061/(ASCE)HE.1943-5584.0000299, 176-186.

Schilling, K. E., Jha, M. K., Zhang, Y. K., Gassman, P. W., and Wolter, C. F. (2008). "Impact of land use and land cover change on the water balance of a large agricultural watershed: Historical effects and future directions." Water Resour. Res., 44(7), 1-12.

Singh, V., Bankar, N., Salunkhe, S. S., Bera, A. K., and Sharma, J. R. (2013). "Hydrological stream flow modeling on Tungabhadra catchment: Parameterization and uncertainty analysis using SWAT CUP." Current Sci., 104(9), 1187-1199.

Singh, V., and Goyal, M. K. (2016a). "Analysis and trends of precipitation lapse rate and extreme indices over north Sikkim eastern Himalayas under CMIP5ESM-2M RCPs experiments." Atmos. Res., 167, 34-60.

Singh, V., and Goyal, M. K. (2016b). "Changes in climate extremes by the use of CMIP5 coupled climate models over eastern Himalayas." Environ. Earth Sci., 75, 839.

Singh, V., Goyal, M. K., and Chu, X. (2015). "Multicriteria evaluation approach for assessing parametric uncertainty during extreme peak and low flow conditions over snow glaciated and inland catchments." J. Hydrol. Eng., 10.1061/(ASCE)HE.1943-5584.0001217, 04015044.

Snell, S. E., Gopal, S., and Kaufmann, R. K. (2000). "Spatial interpolation of surface air temperatures using artificial neural networks: Evaluating their use for downscaling GCMs.” J. Clim., 13(5), 886-895.

Soleymani, M., and Delphi, M. (2012). "Comparison of flood routing models (case study: Maroon River, Iran)." World Appl. Sci. J., 16(5), 769-775.
Subash, N., and Sikka, A. K. (2014). "Trend analysis of rainfall and temperature and its relationship over India." Theor. Appl. Clim., 117(3-4), 449-462.

SWAT [Computer software]. USDA Agricultural Research Service, Temple, TX.

Taylor, K. E., Stouffer, R. J., and Meehl, G. A. (2012). "An overview of CMIP5 and the experiment design (link is external)." Bull. Am. Meteorol. Soc., 93(4), 485-498.

Thompson, J. R., Gavin, H., Refsgaard, A., Sørenson, H. R., and Gowing, D. J. (2009). "Modelling the hydrological impacts of climate change on UK lowland wet grassland." Wetlands Ecol. Manage., 17(5), 503-523.

Thompson, J. R., Sorenson, H. R., Gavin, H., and Refsgaard, A. (2004). "Application of the coupled MIKE SHE/MIKE 11 modelling system to a lowland wet grassland in southeast England." J. Hydrol., 293(1), 151-179.

Vansteenkiste, T., Tavakoli, M., Ntegeka, V., Willems, P., De Smedt, F., and Batelaan, O. (2013). "Climate change impact on river flows and catchment hydrology: A comparison of two spatially distributed models." Hydrol. Processes, 27(25), 3649-3662.

Wilby, R. L., Dawson, C. W., Murphy, C., O'Connor, P., and Hawkins, E. (2014). "The statistical downscaling model-Decision centric (SDSMDC): Conceptual basis and applications." Clim. Res., 61(3), 259-276.

Zhang, Z., Lu, W., Chu, H., Cheng, W., and Zhao, Y. (2014). "Uncertainty analysis of hydrological model parameters based on the bootstrap method: A case study of the SWAT model applied to the Dongliao River Watershed, Jilin Province, Northeastern China." Sci. China Technol. Sci., 57(1), 219-229.

Zucco, G., Tayfur, G., and Moramarco, T. (2015). "Reverse flood routing in natural channels using genetic algorithm." Water Resour. Manage., 29(12), 4241-4267. 